To appear in Language 83, June 2007

\title{
TRANSMISSION AND DIFFUSION
}

\author{
William Labov, University of Pennsylvania
}

\begin{abstract}
The transmission of linguistic change within a speech community is characterized by incrementation within a faithfully reproduced pattern characteristic of the family tree model, while diffusion across communities shows weakening of the original pattern and a loss of structural features. It is proposed that this is the result of the difference between the learning abilities of children and adults. Evidence is drawn from two studies of geographic diffusion. (1) Structural constraints are lost in the diffusion of the New York city pattern for tensing short- $a$ to four other communities: northern New Jersey, Albany, Cincinnati and New Orleans. (2) The spread of the Northern Cities Shift from Chicago to Saint Louis is found to represent the borrowing of individual sound changes, rather than the diffusion of the structural pattern as a whole.

* The work reported here is largely based on the research for the Atlas of North American English (Labov, Ash \& Boberg 2006). Support is gratefully acknowledged from NSF under grants BNS91-11637, SBR 92-22458 and SBR 9811487, and from NEH under grant RT-21599-94. I am indebted to Gillian Sankoff for many important contributions from her work on language change across the lifespan. The work of Don Ringe and his associates on family tree modeling and cladistics is an essential basis for the argument advanced here. For the key association between the weakening of linguistic change in outward diffusion and adult language learning, I am indebted to an intervention of Miriam Meyerhoff at a workshop on linguistic change in progress at the 2003 Summer Institute at East Lansing. Daniel Johnson has provided a number of valuable insights and corrections.
\end{abstract}


1. FAMILY TREE AND WAVE MODELS OF CHANGE. Throughout the history of linguistics, two models of linguistic change have co-existed in an uneasy relationship. The family tree model has been the principal guide and major output of the comparative method. Yet all linguists agree that there are some situations where the effects of a wave model must be recognized, registering the influence of distinct terminal branches of the tree on one another. Such wave effects are seen most clearly in communities with extended periods of bilingualism, in the formation of pidgins and creoles, and in the major Sprachbund areas in which features spread across family trees that are not related in any other way. Contact effects may appear as inextricably embedded in the reconstruction of normal linguistic development. Ringe, Warnow and Taylor 2002 [hereafter RWT] present their current best tree for Indo-European as Figure 1, with the Germanic languages branching from the major node that includes Balto-Slavic (Old Church Slavonic, etc.) and Indo-Iranian (Vedic, etc.). Yet as suggested by the dashed arrow (my addition to the diagram), Germanic shares many characters with the Italo-Celtic branch that split much earlier from the main I-E development. The authors find that this situation points to the modification of the family-tree descent characters by later contact:

This split distribution of character states leads naturally to the hypothesis that Germanic was originally a near sister of BaltoSlavic and Indo-Iranian. . . that at a very early date it lost contact with its more easterly sisters sand came into close contact with the languages to the west; and that that contact episode led to extensive vocabulary borrowing at a period before the occurrence in any of the languages of any distinctive sound changes that would have rendered the borrowings detectable. -p. 111.

This is of course only one of innumerable findings of the effect of language contact, from Schmidt 1871 through Weinreich 1968 and beyond. Bloomfield's discussion of the limitations of the family tree model includes a diagram with this very example of Italic influence on Germanic, adapted from Schrader's original (1933:316). I cite RWT here because the contact problem is foregrounded in one of the most recent and sophisticated developments of the family tree model. It would seem then that any general view of language descent must be prepared to integrate 
the two models of language change. I hope to show here that they are modeling linguistic processes that are quite different in their mechanism and their effects, the results of different types of language learning.

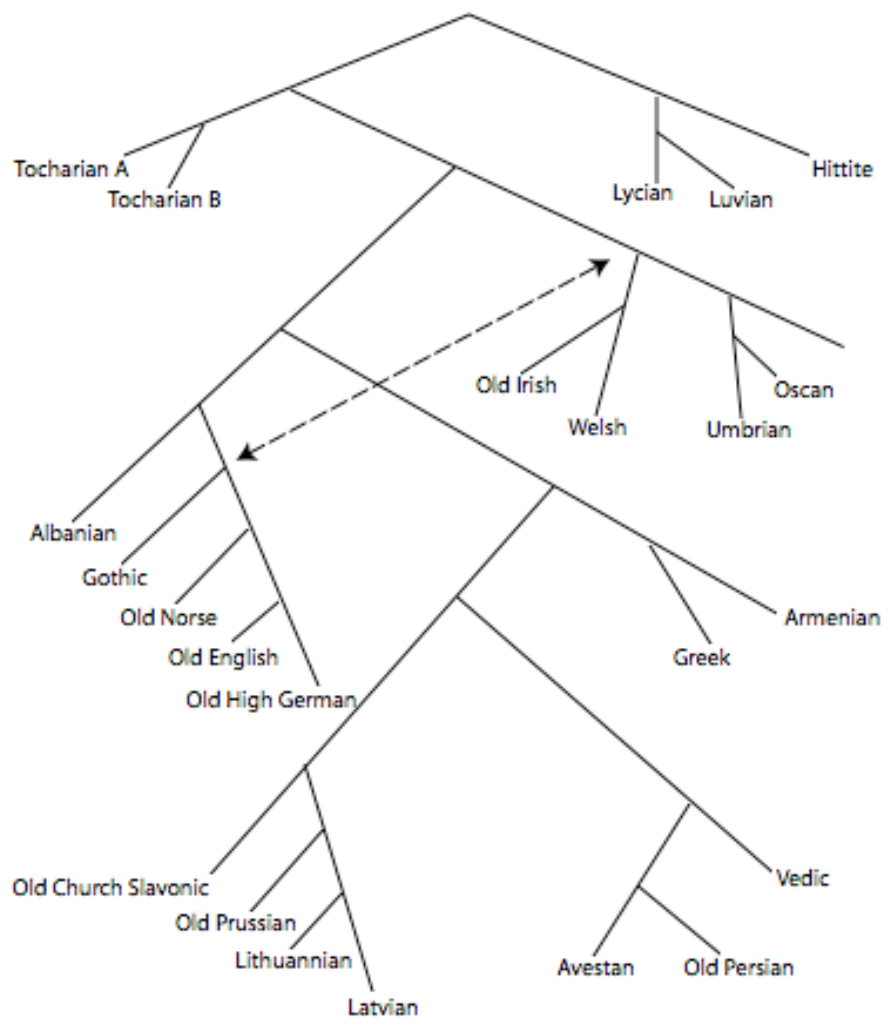

FIGURE 1. Best Indo-European family tree (Ringe, Warnow \& Taylor 2002), with indications of shared characteristics of Germanic with Italo-Celtic branch. 
1.1. DEFINING TRANSMISSION AND DIFFUSION. We begin with the concept of linguistic descent, the basic concept that defines the family tree model. Bloomfield's chapter on the comparative method states the conditions under which we can recognize one language as a later stage of another (1933:316 ff); Hoenigswald (1960) devotes a chapter to the formal definition of mother, daughter, and sister relations. The formulation of linguistic descent given by RWT (p. 63) goes beyond the relationship of the linguistic forms, and introduces into the definition the social process of linguistic acquisition that is the main focus of this paper:

A language (or dialect) $\mathrm{Y}$ at a given time is said to be descended from language (or dialect) $X$ of an earlier time if and only if $\mathrm{X}$ developed into $\mathrm{Y}$ by an unbroken sequence of instances of native-language acquisition by children. ${ }^{1}$

This unbroken sequence of native-language acquisition by children is here termed linguistic transmission. The continuity of dialects and languages across time is the result of the ability of children to replicate faithfully the form of the older generation's language, in all of its structural detail, with consequent preservation of the distances of the branches of the family tree. But linguistic descent can be preserved even when this replication is imperfect, that is, when language changes. This is the normal type of internal language change, termed 'change from below' or change from within the system as opposed to 'change from above' or the importation of elements from other systems (Labov 1966). ${ }^{2}$ Change from below may involve the systematic interaction of social, cognitive or physiological factors that is responsible for increasing distances between the branches over time. Such internal changes are generated by the process of incrementation, in which successive cohorts and generations of children advance the change beyond the level of their caretakers and role models, and in the same direction over many generations (Labov 1994: Ch. 14). Incrementation begins with the faithful transmission of the adult system, including variable elements with their linguistic and social constraints (Labov 1989a, Roberts 1993). These variable elements are then advanced further in the direction indicated by the inherited age vectors. ${ }^{3}$ Children's incrementation of the change may take the form of increases in frequency, extent, scope or specificity of a variable. ${ }^{4}$ 
When entire communities move, they carry with them the agents of transmission and incrementation. Describing the development of new colonial dialects, Trudgill argues that 'most of the complicated work leading to the eventual establishment of a new, single norm will be carried out by children under the age of eight. . . hence the deterministic nature of the process, and the similarity of outcomes from similar mixtures.' (2004:28)

As noted above, analyses within the family tree model regularly report the effect of changes that diminish the distances between branches of the family tree. This may happen spontaneously, when parallel branches converge through independently motivated changes, but more often it is the result of contact between the speech communities involved and the transfer of features from one to the other. This transfer across branches of the family tree is here designated linguistic diffusion.

The process of comparative reconstruction normally employs the family tree model and cites contact or 'wave model' effects as disturbing elements that limit the precision of the reconstruction. It is assumed what RWT makes explicit: that transmission is the fundamental mechanism by which linguistic diversity is created and maintained, and that diffusion is a secondary process. However, Schmidt's wave model does provide an alternative version in which diffusion is the main mechanism of linguistic change in the citation given above. This process of diffusion first creates a continuous web of linguistic similarities and differences. In Bloomfield's summary:

Schmidt showed that special resemblances can be found for any two branches of I-E, and that these special resemblances are most numerous in the case of branches which lie geographically nearest each other. Different linguistic changes may spread, like waves, over a speech-area, and each change may be carried out over a part of the area that does not coincide with the part covered by an earlier change. The result of successive waves will be a network of isoglosses, Adjacent districts will resemble each other most; in whatever direction one travels, differences will increase with distance, as one crosses more and more isogloss-lines (1933:316).

How then are the discontinuities between languages created in this model? They are the result of a secondary process in which speakers of one particular dialect gain an ascendancy - commercial, political, or cultural - and the ensuing expansion 
of this dialect wipes out the intermediate forms of the original continuum. Thus the divergence of branches in the present sense is the result of the elimination of diversity through dialect leveling. The notion of a basic dialect continuum accords well with the principle of density that Bloomfield introduces in his chapter on dialect geography. Bloomfield does not adopt Schmidt's alternative explanation of diversity, but rather retreats to a view of the family tree model as an ideal pattern that is never realized in reality, without rejecting the idea:

The comparative method ... would work accurately for absolutely uniform speech-communities and sudden, sharp cleavages. (1933: 318)

The view I present here is that the primary source of diversity is the transmission (and incrementation) of change within the speech community, and that diffusion is a secondary process, of a very different character. Such a clear dichotomy between transmission and diffusion is dependent upon the concept of a speech community with well-defined limits, a common structural base and a unified set of sociolinguistic norms. I am well aware that for many scholars, including dialectologists, speech communities form continua without clear boundaries between them (Carver 1987; Heeringa and Nerbonne 2001). ${ }^{5}$ I have been influenced by the fact that the communities I have studied most closely are discretely separated from their hinterland. New York City turned out to be a geographic unity defined by a common structural base (Labov 1966 [2006]) as shown by the match between the department store study and the study of the Lower East Side, and the sharp contrast between out-of-towners and native New Yorkers. So too was Philadelphia, where the geographically random telephone survey matched the long-term study of ten neighborhoods, and the oldest upper-class Philadelphian matched the oldest workingclass Philadelphian in the specifics of the complex short- $a$ split that defines the community (Labov 1989b, 2001). Even more startling uniformity and deeper divisions between speech communities were found by the Atlas of North American English (Labov, Ash and Boberg 2006 henceforth ANAE). The extraordinarily homogeneous vowel system of the Inland North is sharply separated from Canada on the North and the Midland on the South, with a tight bundling of a dozen structural isoglosses. 
For this discussion of transmission and diffusion, I draw from such welldefined communities, and the highly structured patterns that define them. The nature of the inquiry may depend in part on the difference between dialectology in North America and studies in western Europe (Auer and Hinskens 1996, Trudgill 1996, Kerswill 2004). In European studies, the contrast between transmission and diffusion is less prominent since the main phenomena are the transfer of well-known features of older established dialects. We rarely find reports of changes from below that depend upon transmission through incrementation, as in the many new sound changes of North America. A second difference has to do with the degree of involvement with linguistic structure. Most discussions of dialect continua deal with lexical isoglosses, lexical incidence, or unconnected phonetic variables, where the distinction between transmission and diffusion may not be so clear. In fact, the argument that I put forward is dependent upon the study of linguistic changes that operate at a higher degree of abstraction than low-level phonetic shifts, involving grammatical conditioning, word boundaries, and the systemic relations that drive chain shifting.

1.2. STRUCTURAL DIFFUSION. In discussions of the linguistic consequences of language contact, the question of structural borrowing is regularly brought to the fore. There is no question about structural transmission within the community: if structures were not transmitted across generations, there would be no continuity in language. The issue is entirely about what can happen in diffusion.

RWT argue for a strong linguistic constraint against structural diffusion. They state that the essential condition for the family tree model is that morphosyntactic structures are faithfully transmitted across generations, and are not transferred from language to language in normal linguistic development. Thomason and Kaufman 1988 contend that social factors can override linguistic constraints, discounting the impact of any structural factors. Moravcsik 1978 proposes five general principles that delimit language borrowing; but Campbell (1993) offers a critical overview of the validity of such constraints. Hock and Joseph note that 'structural elements usually do not diffuse through borrowing' but are the cumulative results of changes in pronunciation and lexical borrowing (1996:14). Winford 2003 concludes, 'The case for direct borrowing of structure in any of these [bilingual] situations has yet to be 
proved' (p. 64). In a meticulous review of the literature on structural borrowing,

Sankoff concludes that the notion of a 'cline of borrowabilitiy' must be supported:

Though most language contact situations lead to unidirectional, rather than bidirectional linguistic results, conditioned by the social circumstances, it is also the case that linguistic structure overwhelmingly conditions the linguistic outcomes. Morphology and syntax are clearly the domains of linguistic structure least susceptible to the influence of contact, and this statistical generalization is not vitiated by a few exceptional cases(Sankoff 2002:658).

Close investigations of some cases of structural borrowing have shown that they are actually consequences of lexical borrowing:

On the other hand, lexicon is clearly the most readily borrowable element, and borrowing lexicon can lead to structural changes at every level of linguistic structure (Sankoff 2001).

The borrowing of preposition-final constructions into Prince Edward Island French, carefully studied by King (2000), is cited by RWT to support their position that structural borrowing has proved to be an illusion in the few cases that have been studied in sufficient sociolinguistic detail. If this is the case, the contrast between transmission and diffusion is absolute: one copies everything; the other is limited to the most superficial aspects of language: words and sounds. ${ }^{6}$ However, it seems unlikely that the actual situation is so abruptly polarized. Joseph 2000 presents several convincing cases of the diffusion of syntactic structures across languages in the Balkans. The spread of the construction Verb-'not'-Verb may be based on a common lexicalized model with the verb 'want', but there is no such evidence in the replacement of infinitival complementation by finite forms. ${ }^{7}$ In any case, contributors to this debate agree - with the exception of Thomason and Kaufman - that there are structural limitations on what types of linguistic patterns can be transmitted across languages.

\subsection{ACCOUNTING FOR THE DIFFERENCE BETWEEN TRANSMISSION AND} DIFFUSION. It is proposed here that the contrast between the transmission of change within languages and diffusion of change across languages is the result of two different kinds of language learning. On the one hand, transmission is the product of the acquisition of language by young children. On the other hand, the limitations on 
diffusion are the result of the fact that most language contact is largely between and among adults. It follows that structural patterns are not as likely to be diffused because adults do not learn and reproduce linguistic forms, rules and constraints with the accuracy and speed that children display.

This hypothesis is informed by recent studies that have greatly refined our understanding of the extent of changes in language learning ability that take place at the end of the critical period (see the recent reviews of Scovel 2000, Newport 2002). The period of decline in language learning ability extends from roughly 9 to 17 years of age. The experiments of Johnson and Newport 1989 showed that subjects who had acquired a second language after 17 years of age could not reproduce the syntactic judgments of native speakers. Oyama 1973 and Payne 1976 showed that children who arrived in a speech community after the age of 9 did not acquire the local pattern with any degree of precision. However, many recent studies show that adults do have the capacity to change their linguistic systems to a significant degree after this critical period (Sankoff 2004). Real-time replications consistently show some adult movement in the direction of the change (Labov 1994, Ch. 4). A real-time re-study of Montreal French (Sankoff et al. 2001) found a shift from apical to uvular/r/ for about a third of the adults. At the same time, it was observed that no adults showed the total conversion to uvular/r/ that was characteristic of many pre-adolescents.

\section{DifFUSION IN DIALECT GEOGRAPHY. Evidence for the differentiation of} family tree and wave models are here drawn from dialect geography, which provides simultaneous records of both diffusion and transmission. The differentiation of regional dialects yields a fine-grained model of family tree evolution. Dialect geography also focuses our attention upon diffusion, since the distribution of features across contiguous dialects leads to the inference that some have spread in a wave-like process of diffusion from one dialect to another (Trudgill 1974; Bailey et al. 1993; Wolfram and Schilling-Estes 2003), With the advent of quantitative studies in the 1960s, this process of diffusion could be observed in some detail.

2.1. THE DIFFUSION OF (Æ) IN NORWAY. Striking examples are found in Trudgill's 1974 study of the Norwegian dialects of the Brunlanes peninsula. Figures 
$2 a, b$ show the outward diffusion of the variable $(\mathfrak{x})$ in two generations. The numbers on the map represent a scale of lowering from 0 to 500. They indicate both incrementation of the variable in the cities that are the points of origin and the geographic diffusion from them to the next largest cities and ultimately to the small villages of the countryside.

The data from Figure 2 were originally used to support the gravity model of diffusion in which the influence of one city on another is proportional to their population sizes and is inversely related to the square of the distance between them. ${ }^{8}$ But they also illustrate the striking difference between the two types of language change: incrementation in urban speech communities and diffusion across the countryside. In Figure 2a, the towns of Larvik and Stavern have values above 240 for the oldest generation of speakers, over 60 years old; in Figure $2 b$, the middle generation of speakers in those cities show values of over 280 . This increase in the magnitude of the lowering process reflects incrementation as the generating process in the city of origin. ${ }^{9}$

Figure 2 also illustrates the opposite process. As the linguistic variable spreads from its originating center, it expands as a wave of continuous weakening as each new level of (æ) diffuses outward. Figure 2 a displays the steady decline of the variable as one moves away from the city centers to the central rural area, where values under 200 are found. Viewed as a process of diffusion from the city centers, it is a wave of continuous weakening as each new level of $(\mathfrak{x})$ lowering diffuses outward. It is also possible to see Figure 2 as an array of incrementing regions, where each surrounding area exhibits incrementation at its own level, and the only 
(a) Speakers over 60 years of age.

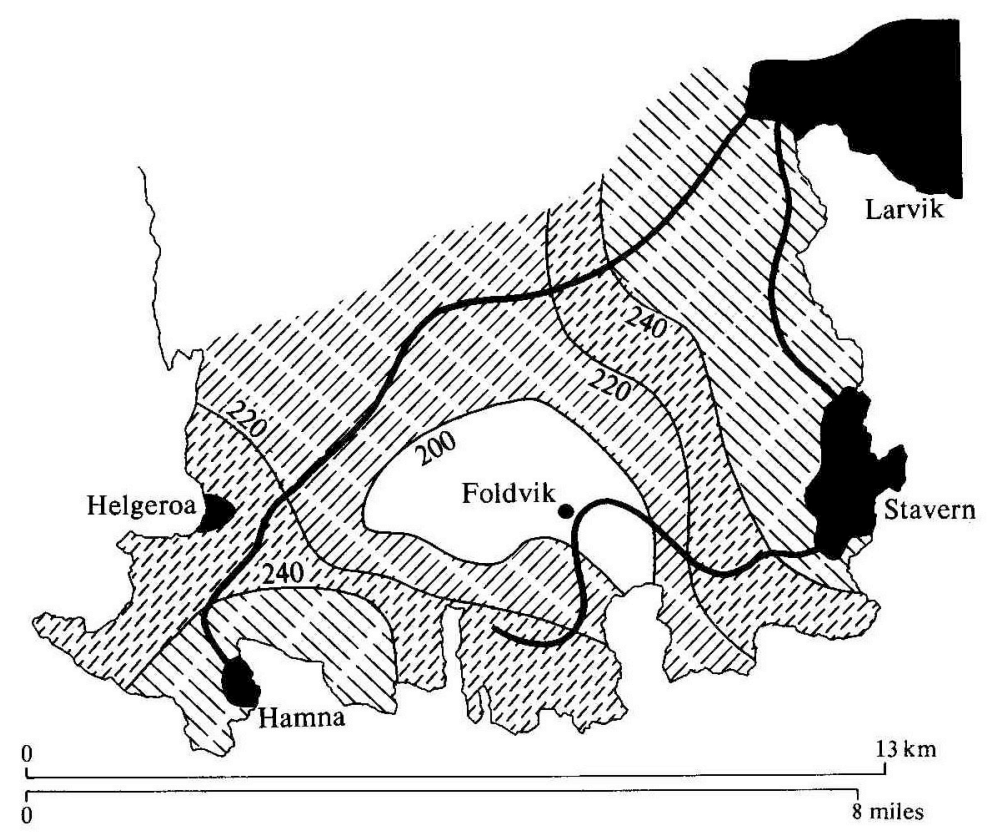

(b) Speakers 25-59 years of age.

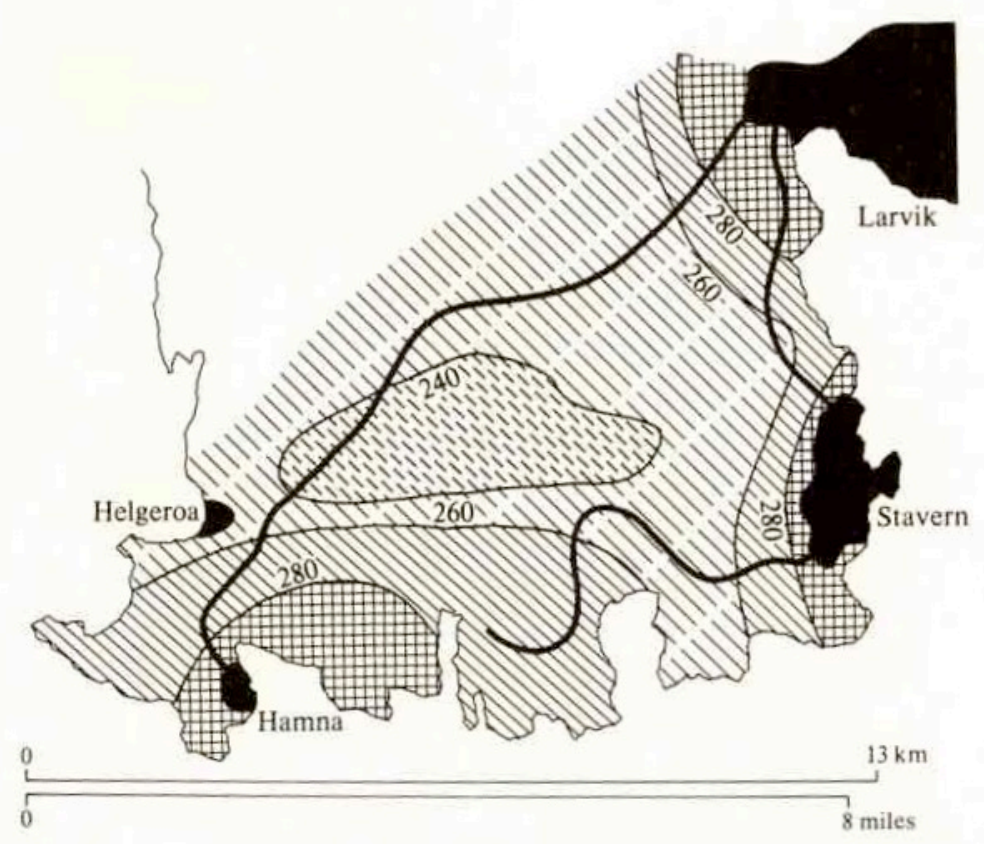

FIGURE 2. Lowering of /æ/ on the Brunlanes peninsula [Trudgill 1974, Map 3.8]. 
difference between the big city and the small town is the time at which the process was initiated.

This issue cannot be resolved with the Brunlanes data, since it is presented as an output phonetic process with no structural conditions or consequences. More complex data from North America to follow will make it possible to distinguish parallel development from diffusion. But given the urban influence indicated in Figure 2, we can expect a certain degree of weakening of the process in the outlying areas, since the expanding forms are copied from adults who are at a relatively conservative level to begin with, and are acquired by adults who change their own speech in a sporadic and inaccurate manner. The next case shows how a sociolinguistic variable diffusing from an urban center can be dramatically reinterpreted in an outlying community.

2.1. ThE DifFusion OF (AN) FROM TEHERAN TO GHAZVIN. The nature of this adult contact is illustrated in the study of the urban dialect of Teheran by Modaressi (1978). One of the sociolinguistic variables he studied was the raising of /a/ to [o] and [u] before nasals, as in the shift of name of the capital city from [teran] to [terun]. This variable shows regular social stratification in Teheran, where the higher the social status of a group, the lower the frequency of (an) raising. Modaressi also studied the small city of Ghazvin, ancient capital of the province of that name, about $150 \mathrm{~km}$ from Teheran.

Figure 3 shows the percent raising of /an/ to /un/ by age and style for Ghazvin and Teheran. Both cities show sharp stylistic stratification and a regular advance of the variable. The solid lines show the values for Teheran, and considerably behind them, dashed lines show the values for Ghazvin. 

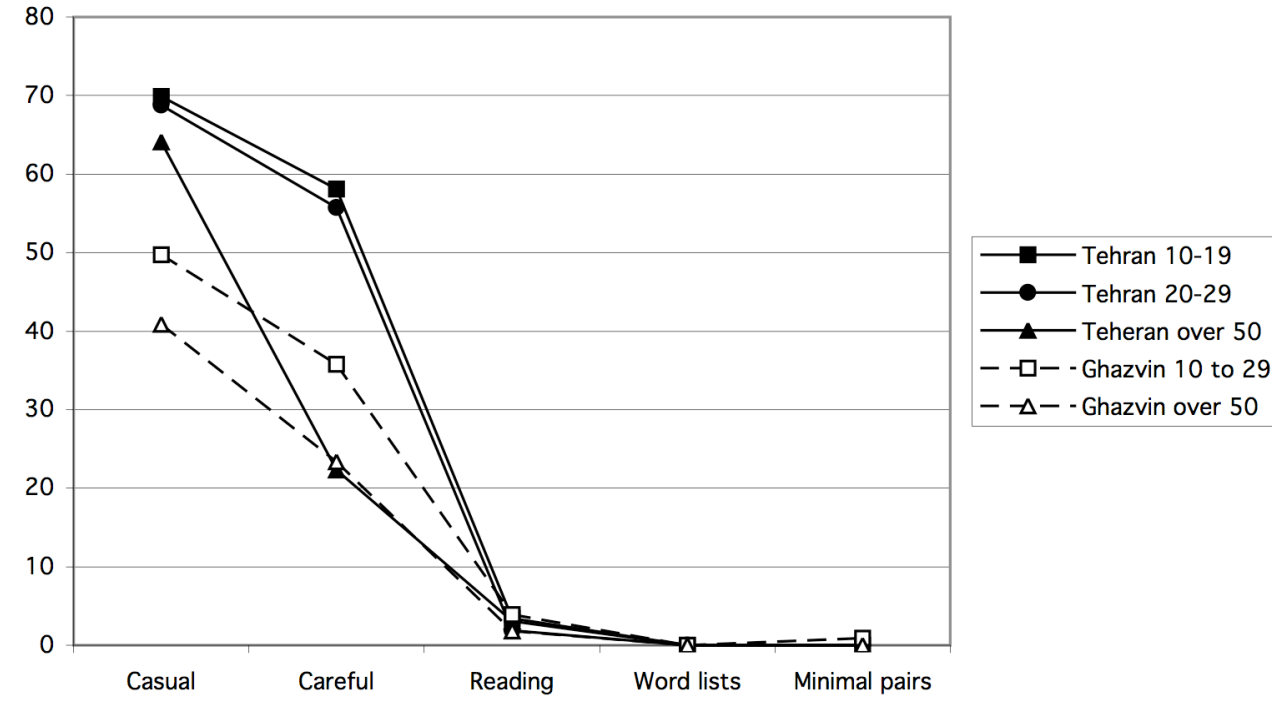

FIGURE 3. Percent raising of (an) by age and style in the Farsi of Teheran and

\section{Ghazvin.}

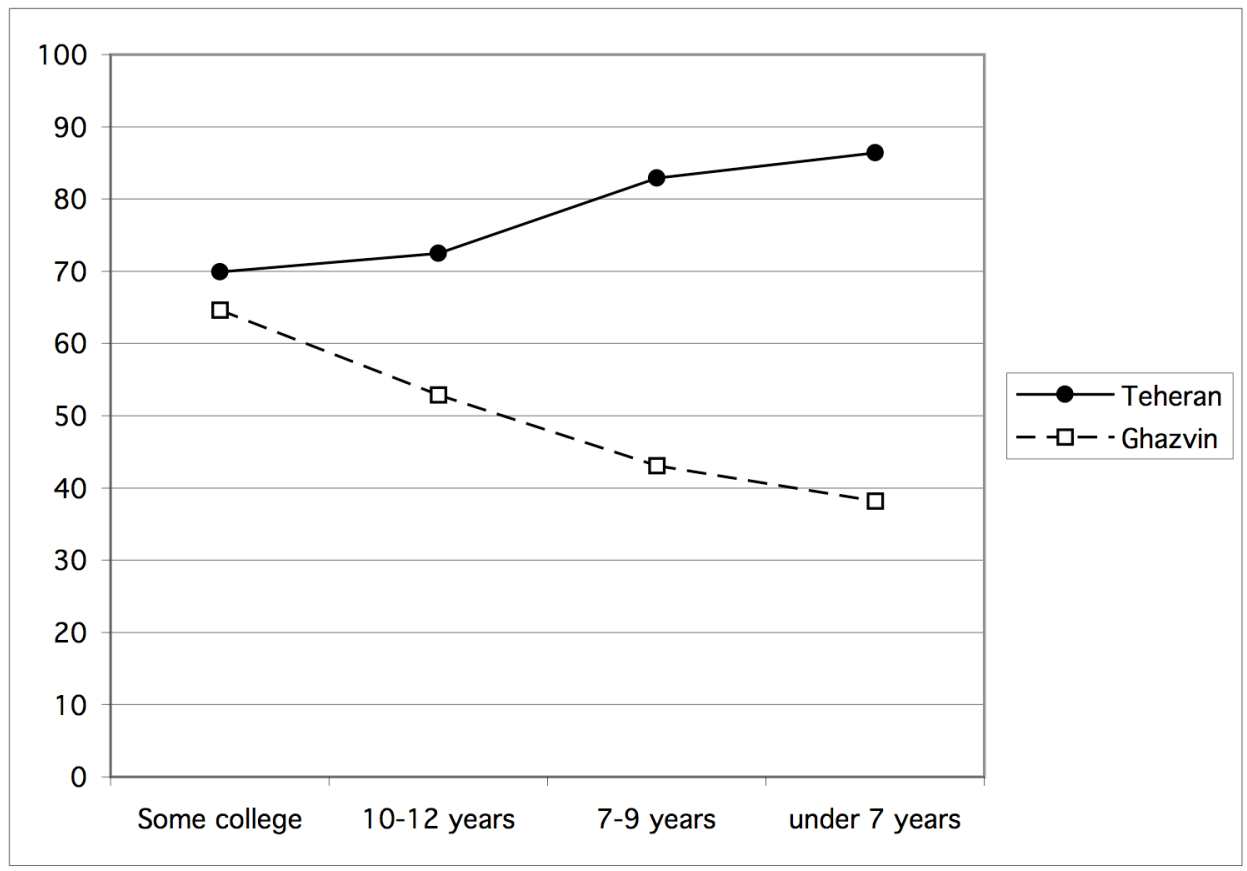

Figure 4. Raising of (an) by education in the Farsi of Teheran and Ghazvin. 
Figure 4 shows this variable by social class, registered by years of education completed. Ghazvin is only slightly behind Teheran for those with some college, but the difference increases with lower educational levels. Furthermore, the two communities show opposite directions of stratification: the more education that citizens of Teheran have, the less they raise /an/ to /un/. In contrast, the more education citizen of Ghazvin have, the more they raise /an/ to /un/. This diagram makes sense only if we infer that the contact between Teheran and Ghazvin is primarily through more educated adults, and that the variable spreads downward in Ghazvin at a low rate through a network of adult contacts. While the original adoption of the Teheran raising of (an) was a matter of speaker-internal accommodation (Trudgill 1986: Ch. 1; Joseph 2000), the speaker-external spread through Ghazvin society follows a reverse pattern of social prestige among adults.

That is not to say that incrementation will also not take place among children in Ghazvin. But they will have inherited the new variable through the filter of adult diffusion with the social evaluation unique to Ghazvin. These examples from dialect geography support the notion that the diffusion of linguistic variables from place to place is carried forward by adults, from whom we expect less advanced rather than more advanced forms of the variables.

The lowering of (æ) in Norway and the raising of (an) in Iran are typical of the many phonetic output rules that we find in studies of sound change in progress. In order to pursue the question of whether structural features can be transmitted, we need to consider more complex patterns than the lowering of /æ/ or raising of (an). The diffusion of the grammatically conditioned short-a split of New York City provides such a case.

3. The diffusion of the NYC short- $a$ system. Almost all North American dialects show a raising and fronting of some members of the historical short-a class (ANAE: Ch. 13). ${ }^{10}$ Phonetic conditioning is always present: in some cases as a continuum, in others as a discrete division into tense and lax distributions. ${ }^{11}$ In some cases the tense and lax classes are phonetically predictable by simple rules; in others, they are not. There are five basic types: 
(a) The nasal system, All short-a before nasal consonants are tense (man, manage, span, Spanish) while all others are lax.

(b) Raised short-a. All words with historical short-a are tense. Found only in the Inland North.

(c) Continuous short-a raising. Short-a words are variably tensed, with vowels before nasal codas leading and vowels before voiceless stops and words with obstruents/liquid onsets (glass, brag) remaining in low front position.

(d) Southern breaking. Breaking of short-a into a low front nucleus, palatal glide and following inglide in the Southern dialect area.

(e) Complex short-a systems. In New York City and the Mid-Atlantic states, a distribution of tense and lax vowels is governed by a complex of phonological, grammatical, stylistic and lexical conditions.

One form of the type (e) distribution is specific to New York City and its immediate environs, first described by Babbitt in 1896. ${ }^{12}$ Babbitt reported that older speakers used the tense variant for the New England broad-a class, while younger speakers appear to have had the modern system as first described by Trager on the basis of his Newark, NJ speech pattern $(1930,1934,1942) .{ }^{13}$ The older and newer systems agree in tensing (in closed syllables) before some front nasal clusters and all front voiceless fricatives, but the newer system expands to include all front nasal codas, all voiceless fricatives and all voiced stops, as indicated in Figure 5. While both systems have tense can't, $\underline{\text { dance, }} \underline{\underline{\text { half}}}, \underline{\text { bath}}, \underline{\text { pass }}$, past, the new system adds $\underline{\text { man }}$,

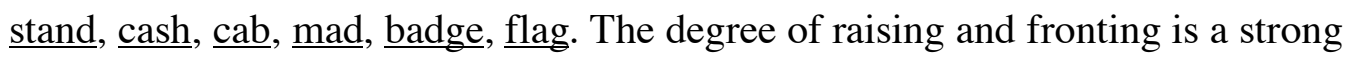
sociolinguistic marker, and New Yorkers frequently lower a tense vowel in careful speech. But the distribution into tense and lax classes is not socially evaluated and is general in the spontaneous speech of community members, to the extent that it is not disturbed by the effects of formal observation (Labov 1966). 


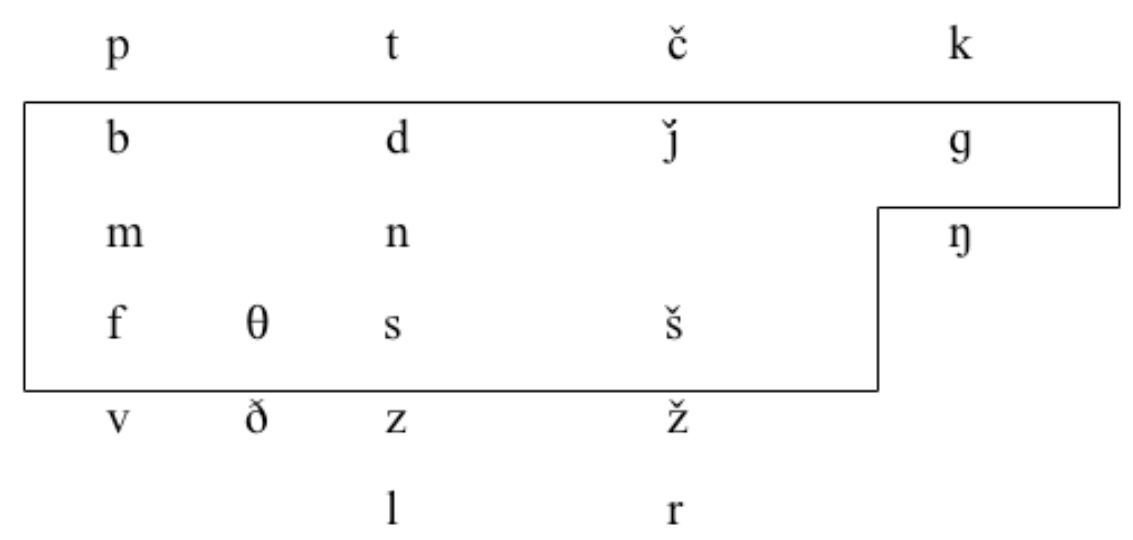

FIGURE 5. Codas that condition tensing of short- $a$ in New York City.

To this basic condition there are added a number of specific conditions:

1. Function word constraint: Function words with simple codas (an, I

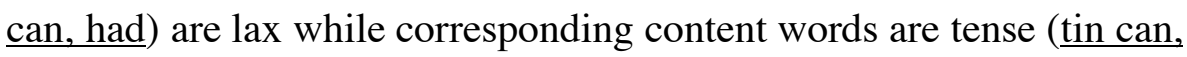
hand, add), while can't, with a complex coda, remains tense. This preserves the contrast of tense can't vs. lax can in environments where the $/ \mathrm{t} /$ is elided or neutralized.

2. Open syllable constraint: Short-a is lax in open syllables, yielding tense ham, plan, cash but lax hammer, planet, cashew).

3. Inflectional boundary closing: Syllables are closed by inflectional boundaries, so that tense forms include planning as well as plan,

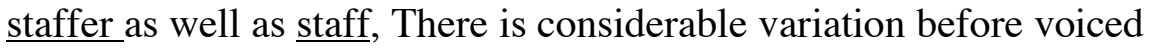
fricatives (magic, imagine, jazz).

4. Initial condition. Initial short- $a$ with codas that normally produce tensing are lax (aspirin, asterisk) except for the most common words (ask, after).

5. Abbreviations: Abbreviated personal names are often lax ( $\underline{\text { Cass, Babs). }}$.

6. Lexical exceptions: There are a number of lexical exceptions: e.g., avenue is normally tense as opposed to lax average, savage, gavel,

7. Learned words: Many learned or late-learned words with short- $a$ in tense environments are lax: alas, carafe. 
Given the lexically specific conditions (4-7), it would seem necessary to analyze this pattern as a phonemic split. However, Kiparsky (1988) argued within the framework of lexical phonology that the patterns of change in progress within the community indicated the presence of a lexically and grammatically conditioned rule. To decide this issue, more information is needed than we now have available on how the pattern is learned. At this point in the discussion, the tense class will be referred to as /æh/ and the lax class as /æ/ without deciding how these classes are generated or stored.

Figure 6 shows the characteristic distribution of tense /æh/ and lax /æ/ for an ANAE speaker from New York City recorded in 1996. Nancy B. was then 65 years old, a homemaker and secretary of Italian-American background. In her speech, only two members of the tense class (one each of bad, bag) were corrected to the lax class during the interview. Otherwise, we observe a clear phonetic separation of the two classes. The tense /æh/ class includes short-a before voiced stops in closed syllables

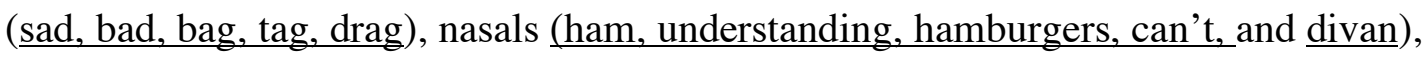
voiceless fricatives (calf, flash, glass, last, grass). In the lax category are corresponding words with short-a in open syllables (animal(s), manatee), function words (have, am, had), and environments that are always lax (happen, attack, black) including following velar nasals (Frank, slang, Sanka). 


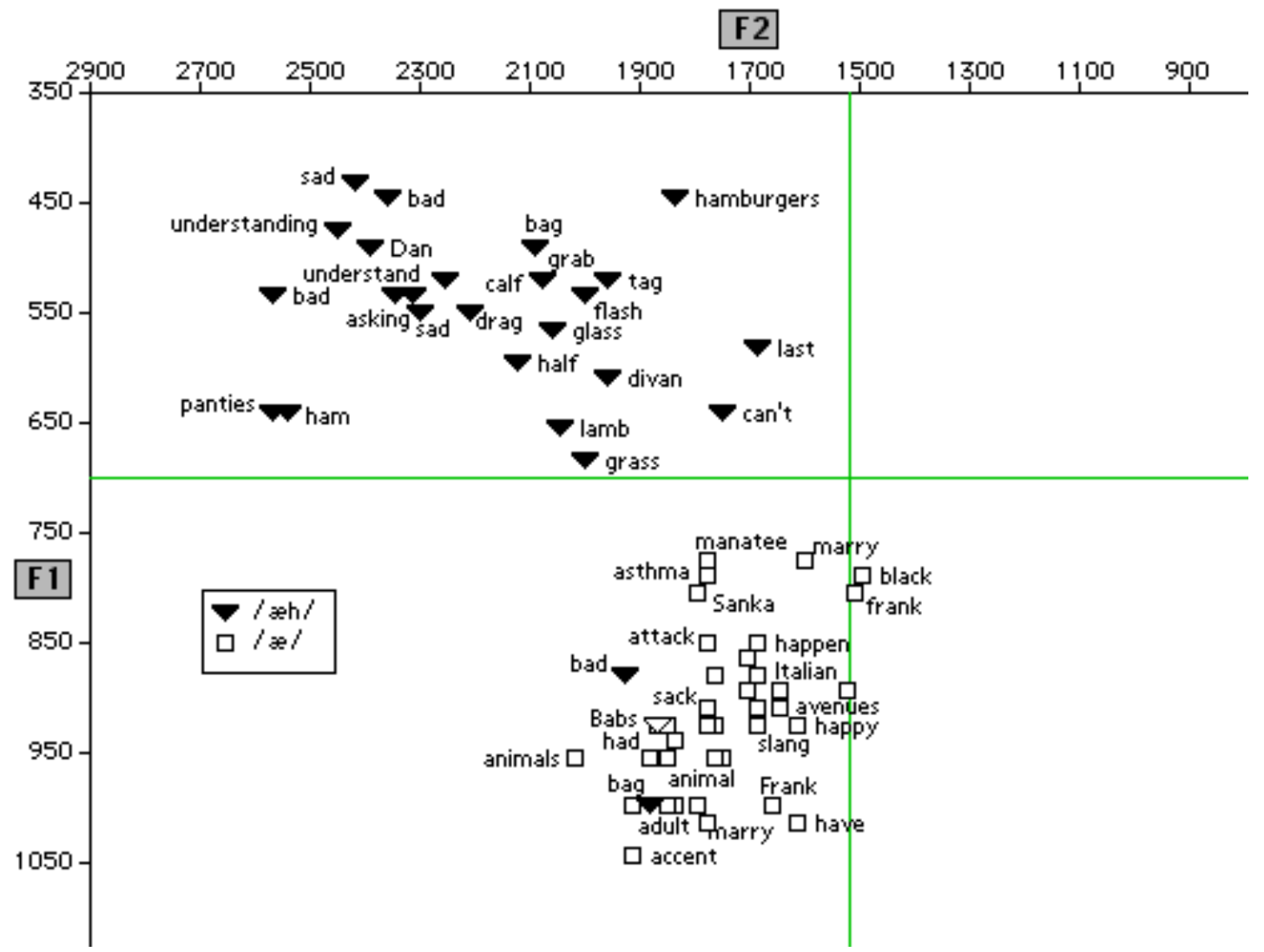

FIGURE 6. Short- $a$ distribution of Nancy B., 65 [1996], New York City, TS 495

The dialect of New York City is confined to the city itself and several neighboring cities in northeastern New Jersey (Weehawken, Hoboken, Jersey City, Newark). ${ }^{14}$ The NYC short- $a$ distribution follows the same distribution throughout this area, and as far as we know, has been stable through most of the twentieth century. It is clear that the New York City short-a system is very far from whatever beginnings it had as a simple, phonetically determined sound change. It has developed the lexical and morphological irregularities characteristic of many late stages of change (Janda and Joseph 2001). It therefore gives us an opportunity to see what happens to this complex structure when it diffuses to other communities.

ANAE shows that the New York City pattern has diffused to four other communities, along the paths shown in Figure 7. 


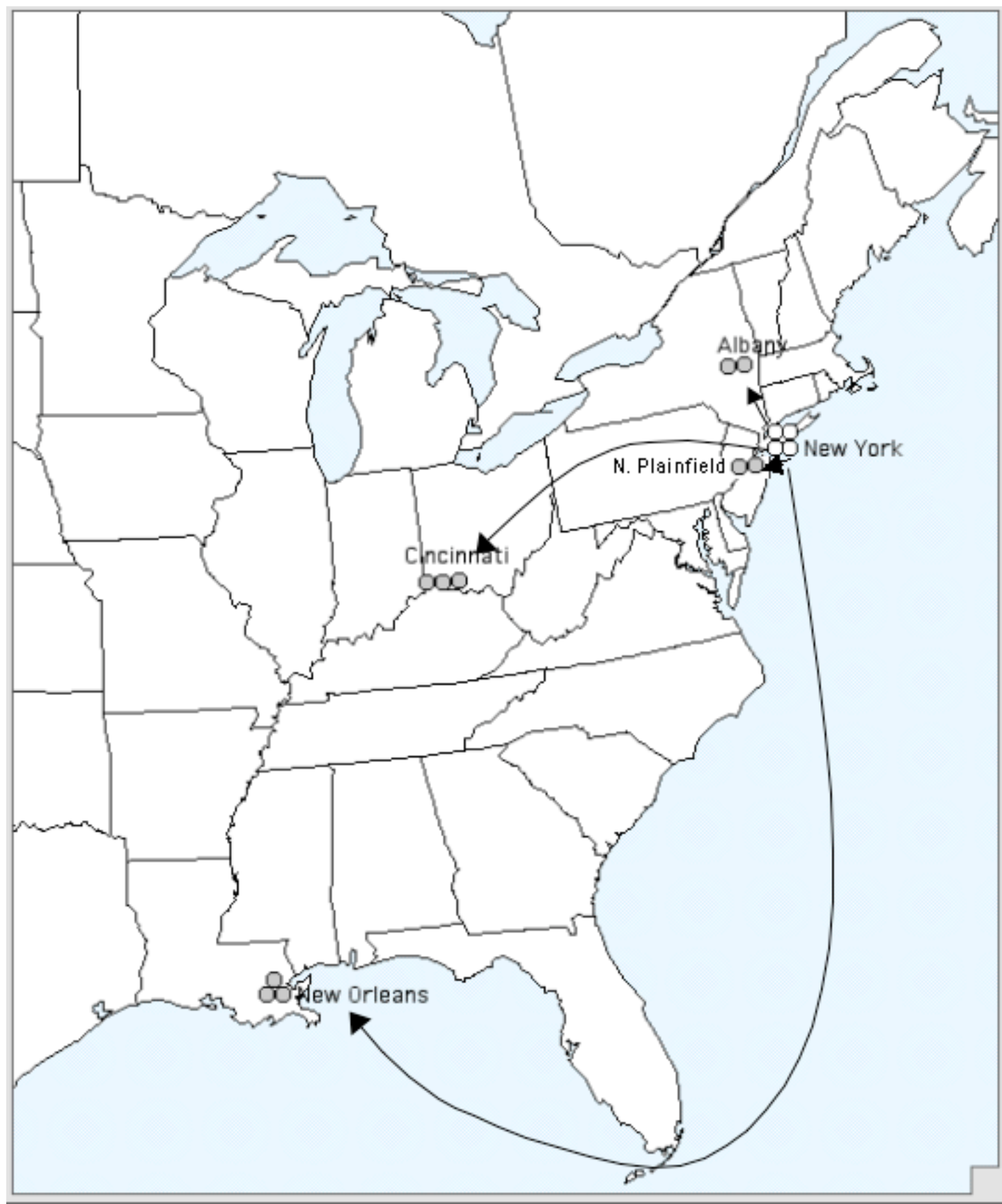

FIGURE 7. Diffusion of the New York City short- $a$ pattern to four other speech communities.

\subsection{DifFusion to NORTHERn New JeRSEY. I was born in Rutherford, New}

Jersey, a small residential, $r$-pronouncing town studded with Dutch farm houses, just outside of the New York City speech community. Though the local dialect that I acquired was an $r$-pronouncing dialect, the short-a system generally conformed to the 
descriptions of the NYC short-a system given above. ${ }^{15}$ But there was a striking difference in the absence of the function word constraint. A very common utterance for all residents of this Northern New Jersey area was, 'Did you say C-A-N or C-A$\mathrm{N}$-T?' since the vowel is tense in both words and the / $\mathrm{t} /$ is often neutralized by a following apical obstruent (as in 'I can't tell you'). Tense vowels are found in am, and, an as well. I originally cited this as an example of how the advance of sound change can override functional constraints, but in the perspective of the present study, it appears as an instance of the loss of structural detail in the diffusion of the NYC short- $a$ system to dialects with which it is in contact.

Cohen 1970 is a detailed study of short-a systems in New York City and in the adjacent areas of Northern New Jersey. He finds that the area closest to New York, between the Hackensack and Hudson Rivers, replicated the NYC features outlined above, with no more variation than we find in the city itself. In the area between the Hackensack and Passaic Rivers, including Rutherford, there is a striking tendency to lose the functional constraint before nasals, so that can, am, an, and are tense. Variable tensing is found in open syllable word types like planet, fashionable. Beyond the Passaic River, the short-a systems are radically different from New York City. ${ }^{16}$

Although the original ANAE design studied cities of 50,000 or more, it was extended to study a number of small towns in the area between New York City and Philadelphia. Two speakers from North Plainfield, NJ, were interviewed. North Plainfield is a residential community of 20,000, located 28 miles southwest of New York City, and 18 miles southwest of Newark, the nearest full representative of the NYC dialect. Like all ANAE subjects, they were both natives of North Plainfield. One was Alex O., an 81 year old retired tool and die maker of Russian/Polish background who was interviewed in 2001. Figure 8 clearly shows that his short-a system follow the basic New York City pattern. The symbols in Figure 8 are cued to the NYC pattern with solid triangles as tense /æh/ and empty squares as lax /æ/. Vowels in closed syllables before voiced stops are tense (cab, bad, glad) and

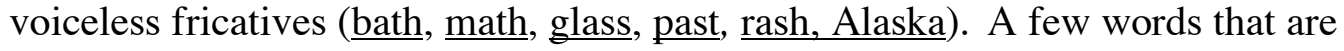
normally tensed in NYC, mostly polysyllables, are found in the lax class: mash, candidate, mansions. ${ }^{17}$ As in NYC, inflectional boundaries close the syllable 
(banning). The open syllable constraint is partially intact, with lax Canada but tense classics. ${ }^{18}$ The lexical exception avenue is tense as in NYC. The crucial difference from NYC is the absence of the functional constraint before nasals as shown in the tense position of am and the auxiliary can along with the noun can. However, had is lax.

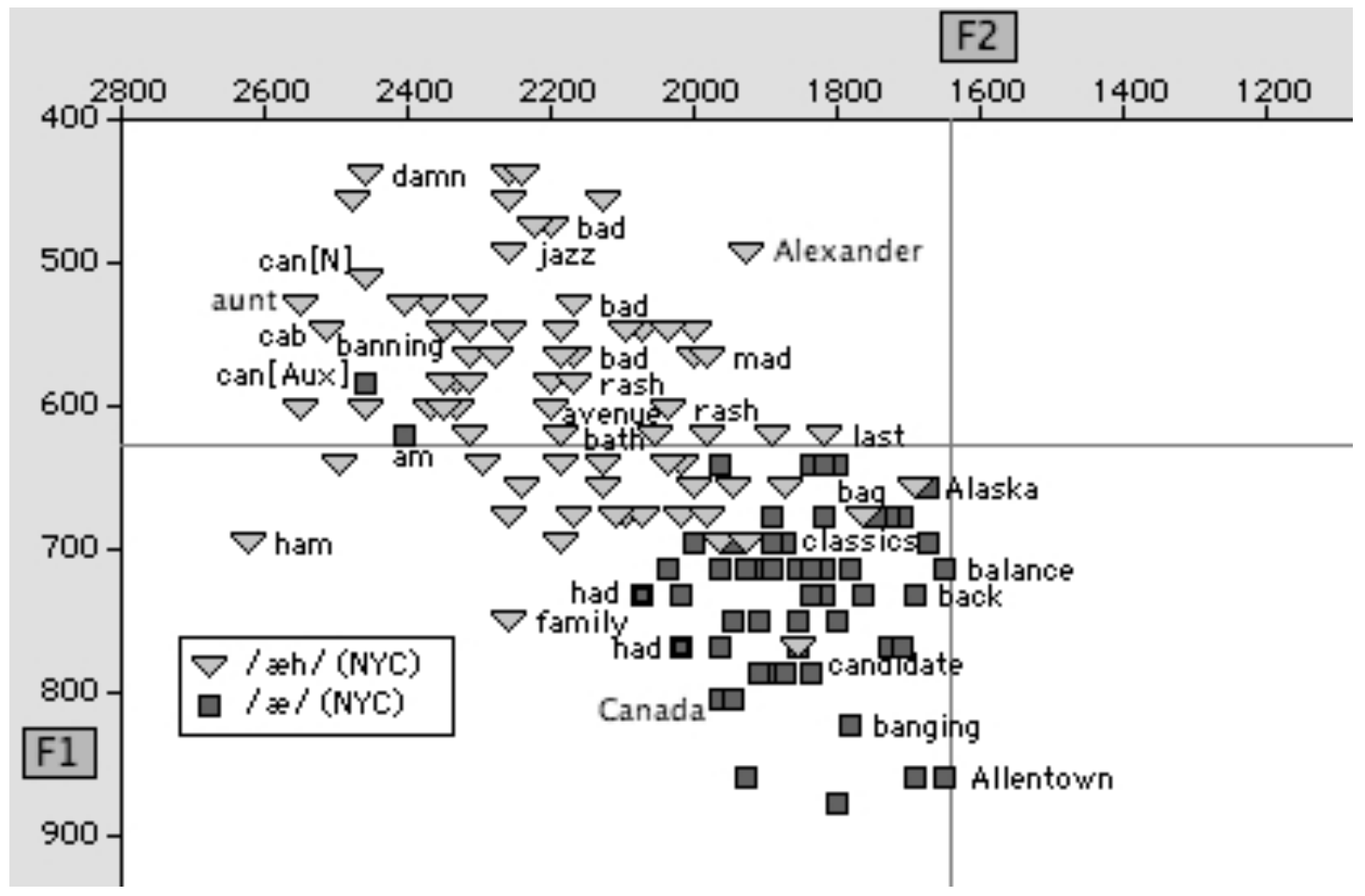

FIGURE 8. Short- $a$ system of Alex O., 81[2001], North Plainfield NJ, TS 815.

The second North Plainfield speaker studied is a younger man, Michael O., 58 years old in 2001, a consultant in criminology of Irish background, and not related to Alex O. He preserves the NYC system in its basic outlines before nasals, voiced stops and voiceless fricatives, but with further loss of structural detail. In his speech we observe the tensing of am and auxiliary can at the same phonetic position as Alex $\mathrm{O}$, but had is also tense. The lexical exception avenue is lax. The open syllable constraint is weaker: camera, damage, Janet, planet, Spanish, Catholic are tense, but manage and castle are lax.

In these cases and those to follow, we recognize the influence of the NYC system by its complex and unusual conditioning class of voiced stops, voiceless fricatives and front nasals, found only in NYC and communities that have a history of 
contact with NYC. A number of lexical and phonetic details may or may not be copied with the basic phonetic pattern. Most subject to loss with diffusion are the open syllable constraint and the function word constraint.

3.2. Diffusion to AlbANY. Albany was actually settled before New York City. It was the second inhabited place in the colonies--established by Henry Hudson in 1609. It had a long and separate history during and after the Dutch period. But the construction of the Erie Canal from 1810 to 1827 led to a steady flow of population from New York City to Albany and westward. It is not surprising then to find a number of lexical maps from the Word Geography of Kurath 1949 that display an affiliation between New York City and the Hudson River valley. Figure 9 traces the distribution of three vocabulary items that are common to the NYC region and the Hudson Valley: the words suppawn for 'corn meal,' barrack for 'hay cock', and teeter-totter for 'seesaw'. Of these, teeter-totter is most likely to survive in New York City today; it was used regularly by Lower East Side subjects in 1963 (Labov 1966).

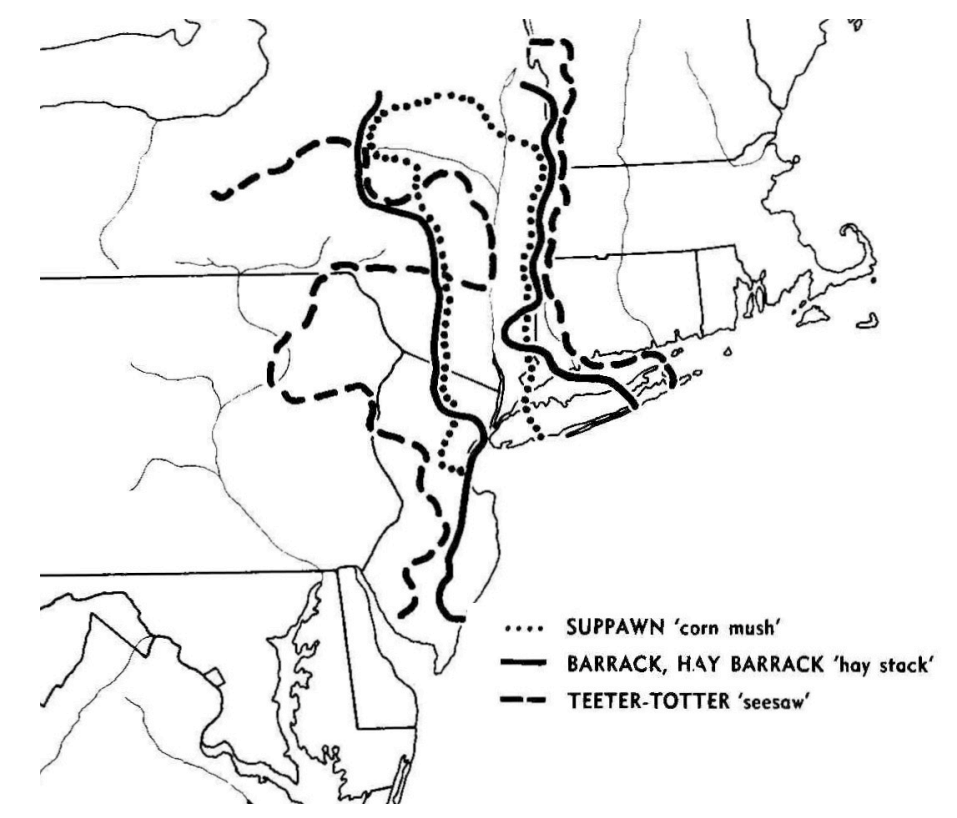

FIGURE 9. The Hudson Valley as a dialect area [from Kurath 1949: Figure 13].

The short-a distributions in New York State outside of the Hudson Valley do not resemble the New York City system. Most of these cities have type b, the wholesale raising of short-a characteristic of the Inland North. New England is 
dominated by the type a nasal pattern. But in Albany, the two ANAE speakers exhibit a striking resemblance to the NYC pattern, the situation illustrated in Figure 10, the short-a distribution of John E. ${ }^{19}$

Listening to Albany speakers, anyone familiar with the New York City phonology will recognize a close relative. The back vowel /oh/ in law and coffee is not only raised to upper mid back position, but also shows the type of rounding ('pursing') that is specific to New York City. The tensed short-a has a strongly fronted nucleus which rises to upper mid and lower high position. As in New York, the tense set is a complex configuration of voiced stops, voiceless fricatives and front nasals. However, a close examination of the specifics of the Albany system shows some marked departures from NYC.

As in Figure 8, the symbols in Figure 10 are keyed to the tense/lax classes of NYC. Empty squares in the upper left region and solid triangles in the lower right are deviations from the NYC system. The diagonal line indicates the division between the vowels that are perceptually tense at upper left and perceptually lax at lower right. As in NYC, short- $\underline{a}$ before voiced stops and voiceless fricatives are tense (bad, half, basketball, after). But Albany shows the loss of the open syllable constraint: two

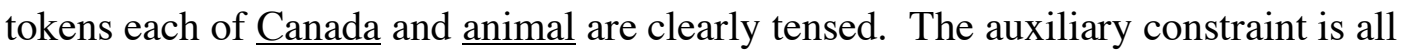
but gone. A stressed token of and is at the upper end of the tense distribution, and three of the four tokens of have are clustered in the lower part of the tense area, along with after. The word avenue, which normally has a tense vowel in $\mathrm{NYC}$, is lax here.

The diffusion northward of the short-a system to Albany represents a transportation of the general phonetic basis for the NYC split, but not a faithful copy. The opposition of closed versus open syllables is lost, and with it, the grammatical opposition between tense planning and lax planet. What remains is the separation of the tokens into a bimodal distribution of allophones determined by the unusual phonetic constraints that are found in NYC-voiced stops and voiceless fricatives, along with front nasals. 


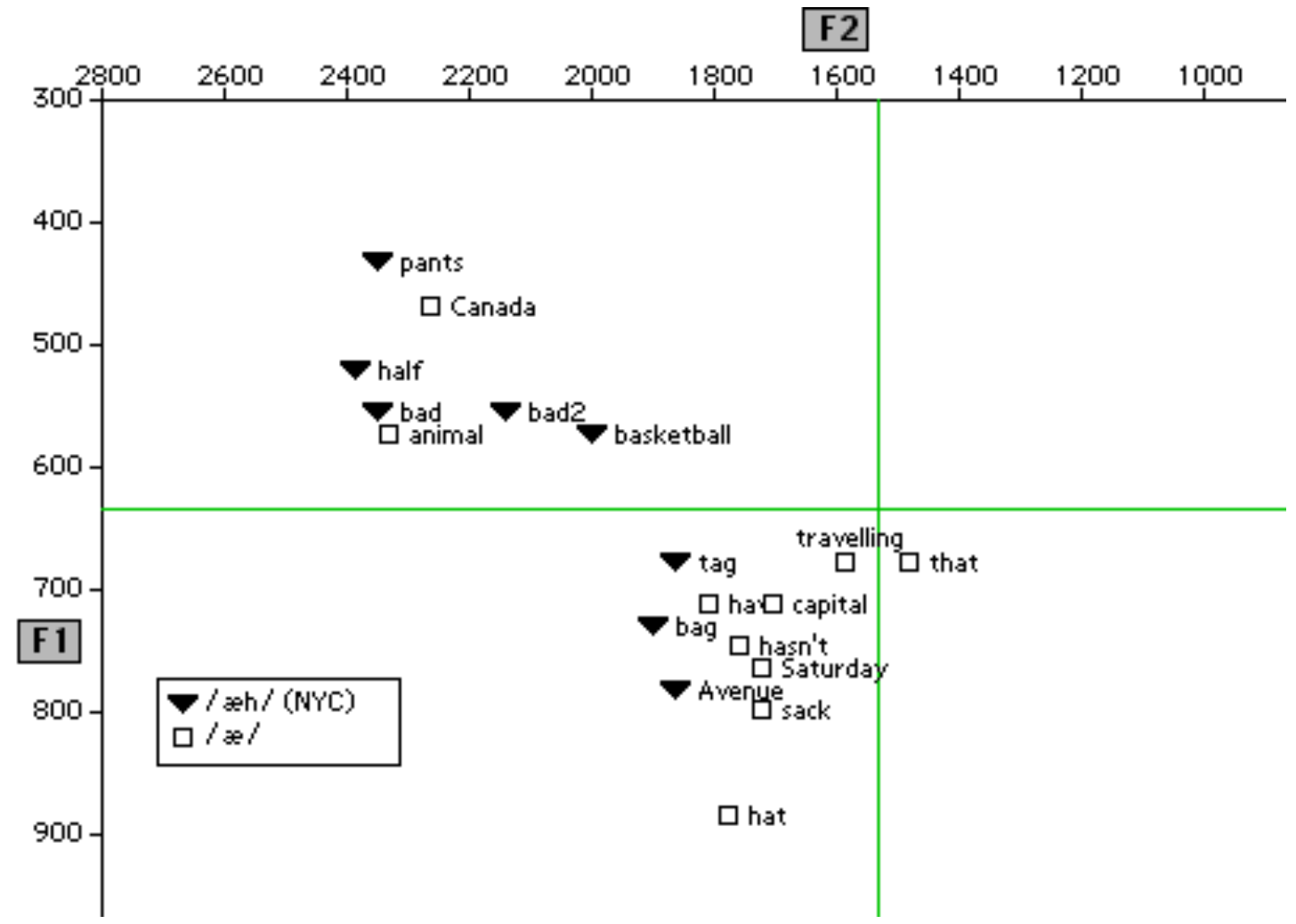

FIGURE 10. Short- $a$ tokens of John E., 46 [1995], Albany NY, TS 353.

3.3. Diffusion to Cincinnati. The city of Cincinnati is represented by four ANAE speakers; three are analyzed acoustically. Figure 11 shows the characteristic short- $\underline{a}$ system as displayed in the productions of a 58-year-old woman, Lucia M., a former teacher of Irish/German background who was then working as an accountant at a Savings and Loan firm. One can observe the basic division into tense and lax sets characteristic of NYC. The tense set includes short a before nasals (ham, aunt, $\underline{\text { chance, }} \underline{\text { divan }})$, voiceless fricatives ( $\underline{\text { cash}}, \underline{\text { hashbrowns }})$ and voiced stops ( $\underline{\mathrm{mad}}, \underline{\mathrm{sad}}$, dad). Boberg and Strassel noted the resemblance between the Cincinnati and NYC short-a patterns, and interviewed 15 more subjects with considerable attention to short-a (Boberg and Strassel 2000, ANAE Chapter 19). 


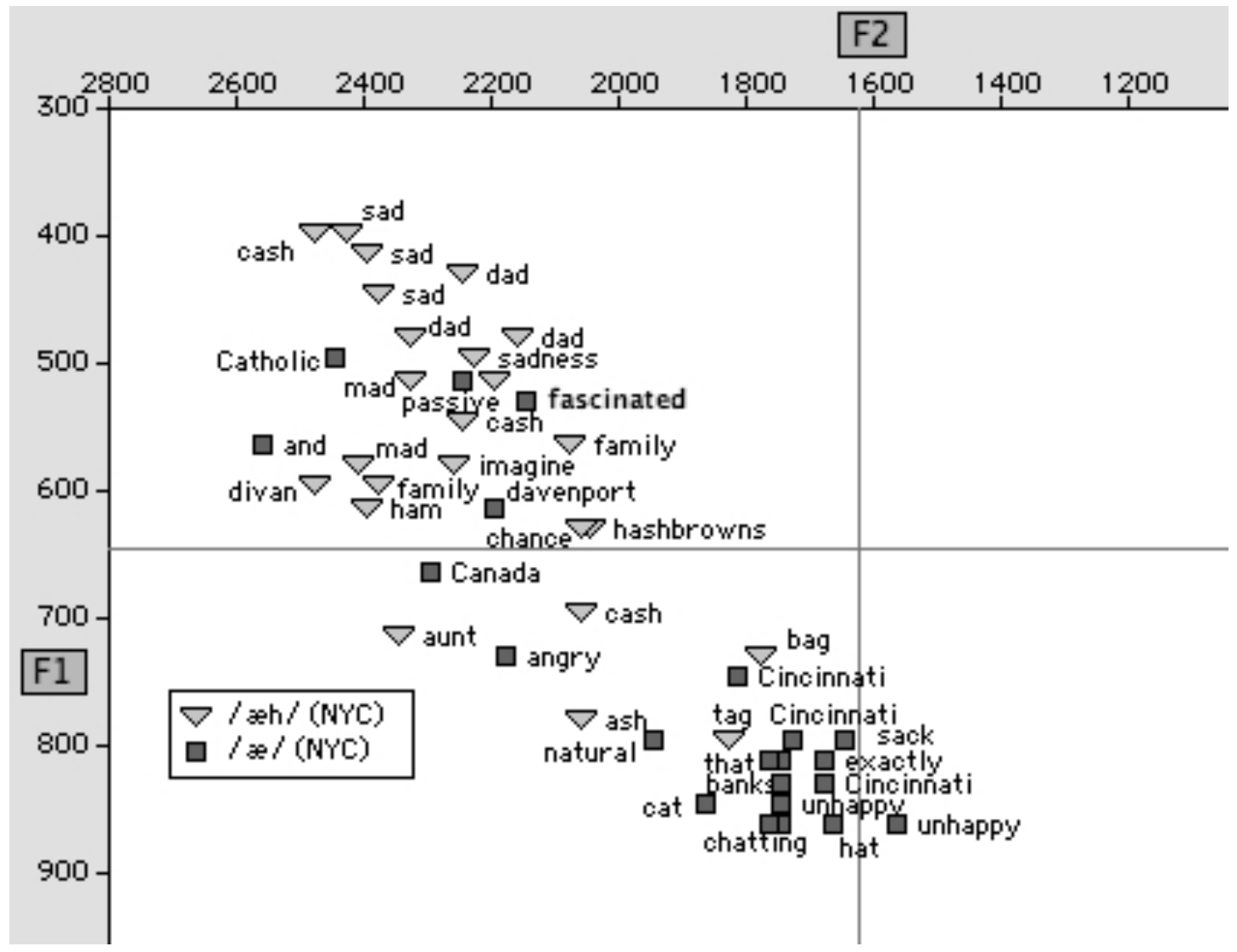

FIGURE 11. Short-a system of Lucia M., 58[1994], Cincinnati OH, TS 120.

We find in Cincinnati the same type of deviations from the NYC pattern as in North Plainfield and Albany, appearing in Figure 11 as dark squares among the light triangles. The open syllable constraint is consistently violated, as shown in in Catholic, passive, fascinated, davenport, and Canada. In addition, the function word and is found in the tense group, reflecting the loss of this grammatical constraint. Among the lax tokens, the only clear exception to the NYC pattern are vowels before /g/.

Our first task is to account for the resemblance between NYC and Cincinnati in historical terms - in the original settlement pattern or by later contact. Cincinnati lies squarely in the Midland area which was generally populated by a settlement stream that passed through Philadelphia, western Pennsylvania and Kentucky. But while the Mid-Atlantic region of Baltimore, Wilmington and Philadelphia limits

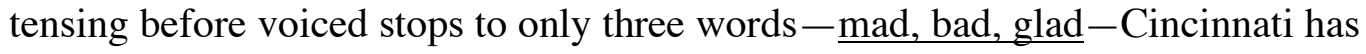


general tensing before all voiced stops except $/ \mathrm{g} / .^{20}$ While the Mid-Atlantic region limits tensing to codas with front voiceless fricatives, Cincinnati resembles NYC in tensing before palatal fricatives as well. It should also be noted that the five oldest Cincinnati subjects interviewed by Boberg and Strassel had uniform tensing before voiced fricatives, an environment that is variable in NYC. ${ }^{21}$

We are fortunate in having available very detailed accounts of the settlement of Cincinnati. From 1943 to 1963, the Historical and Philosophical Society of Ohio published a Bulletin with contributions from many local scholars. I will present this new evidence on the settlement history of the Cincinnati speech community in some detail, since it has not previously been related to linguistic matters and bears crucially on the relation between the New York City and Cincinnati short- $a$ pattern. The great majority of the settlers whose origins are identified were raised in New Jersey not far from the North Plainfield area just considered.

The history of the city now known as Cincinnati began in 1787, when Congress opened to settlement the land between the Allegheny Mountains and the Mississippi River (Shepard 1949). Several prominent veterans of the Revolutionary War made the first purchase of land near the mouth of the Miami River. Major Benjamin Stites was a native of Scotch Plains in Union County, NJ, who first became acquainted with the Cincinnati region during the French and Indian wars, and conveyed his enthusiasm for settlement to Judge John Cleves Symmes. Symmes was a native of New York who moved to New Jersey at the age of 28. Symmes and associates purchased 330,000 acres between the Great Miami and Little Miami Rivers. With Symmes' party was Ephraim Kibby, a hunter, road builder and Indian fighter who afterwards served in the territorial legislatures; his birthplace was listed as NJ in 1754 (but Sjodahl 1964 argues that he came to NJ to enlist in the $4^{\text {th }} \mathrm{NJ}$ Regiment from his family home in Somers, Connecticut.) Shortly afterwards, a party of 26 settlers headed by Stites arrived. ${ }^{22}$ His children Benjamin Jr., Elijah and Hezekiah were all prominent in the early history of the area; Benjamin Jr.'s wife is said to have been the first white woman in Cincinnati.

Among the early settlers, the Burnet family had great influence in the first half of the $19^{\text {th }}$ century (Stevens 1952). Dr. William Burnet (1730-91) was a native of NJ 
of Scottish parents, a member of the Continental Congress and Surgeon-General during the Revolutionary War. One son William went to Cincinnati in 1789 but returned in 1791. In 1796, two other sons, Jacob and George, moved to Cincinnati; they both became lawyers and took part in the territorial government of Ohio. Burnet's youngest son Isaac came to Cincinnati in 1804, studied law with Jacob, and married a woman from a Cumberland County, PA family. He became the county prosecuting attorney, and was succeeded by another New Jersey man, Joseph Crane. Isaac Burnet and Crane then opened the Dayton Manufacturing Company with two other businessmen, one from New Jersey, the other from Rhode Island. Isaac Burnet was elected mayor of Cincinnati in 1819, and served for 12 years.

At a meeting of The Cincinnati Pioneer Association in 1844, it was noted that the oldest pioneer present was William Dennison, born in New Jersey. A monument to another prominent early pioneer, Daniel Drake, shows that he was born in 1785 in Essex County, NJ (Blankenhorn 1950). A study of the Old Stone Episcopal Church centered around Reverend John Collins, who came to Cincinnati in 1802 from Gloucester County, NJ.

In 1957, Shepard discovered a trunk full of letters in the attic of a house in North Bend, a suburb of Cincinnati. Written by a neighbor who had left the farming district of New Jersey, they were addressed to relatives in New Jersey, describing in alluring terms the new tract of land purchased by Judge Symmes (Shepard 1957).

This view of the linguistic formation of the Cincinnati dialect is reasonably clear. From its founding in 1788 to at least the middle of the $19^{\text {th }}$ century, Cincinnati society was dominated by people from central New Jersey. Settlers were drawn from many other areas, like Rhode Island, Connecticut and Pennsylvania, but a typical board of directors had three of four members from New Jersey. The great majority of the community leaders identified in these historical notes came from the area of New Jersey which now has the short-a system of Figure 8.

This was not a community migration of $10-20,000$ people that was characteristic of settlements moving westward from New England. People moved as individuals, or in small groups, occasionally returning, and often married outside of their groups of common origin. At least for the earliest period, the NYC short-a 
system was transported by adults, that is, a case we would have to classify as diffusion rather than transmission. The diffusion was effective: with its New Jersey origins and continued contact with the home communities, the Cincinnati dialect resisted leveling with other Midland dialects to the end of the $20^{\text {th }}$ century.

This second diffusion has created a further distance from the original NYC pattern. The open syllable constraint is practically gone in the Cincinnati version, as well as the grammatical constraint. Furthermore, two phonetic parameters have been generalized. Voiced fricative codas lead to tensing much more consistently than in New Jersey or New York. And the constraint against tensing before velars is extended from nasal to oral consonants.

At this point we have to consider the possibility that the short-a systems of Plainfield, Albany and Cincinnati represents an original stage of the NYC pattern, which was faithfully transmitted to New Jersey and Albany and then perhaps less faithfully westward, while the features that now distinguish $\mathrm{NYC}$-particularly the grammatical constraint--are later developments. ${ }^{23}$ This would correspond to the version of the wave model elaborated by Wolfram and Schilling-Estes 2003.

The earliest account we have of the NYC short-a system is Babbitt 1896. Our present argument presumes that a century earlier, the NYC system was similar to what it is now. If our speculations on the earlier history of the NYC short-a system are correct, it had its origins in the British broad-a system at a time when the British vowel was fronted (Ferguson 1975, Labov 1994), and it has obviously undergone considerable change from that point. The grammatical constraint would be one such innovation. On the other hand, the open syllable constraint is shared by all versions of the broad-a class and the NYC system. The question then remains, is there any evidence that the grammatical constraint does date back to the time of the Revolutionary War? Though we have no direct evidence, indirect evidence characteristic of the comparative method stems from the fact that the one other dialect which is clearly cognate with NYC shares this constraint. Function words can, am, an are also lax in the Philadelphia short-a system. ${ }^{24}$ The likelihood that these are independent innovations is not very great, considering the fact that no other case has been reported in North America or in England across the wide variety of short-a 
developments. As we have seen, the changes that have taken place are in the other direction: the shift of short-a in function words from lax to tense. ${ }^{25}$ We therefore proceed with the most likely scenario, that the British broad-a class was transformed early in the formation of the American English of the two major cities of the MidAtlantic states with the common innovation of a constraint on function words that has been faithfully transmitted within these speech communities but does not diffuse to others.

The next case shows a resemblance to New York City in a broader range of phonetic phenomena, and more evidence of commercial relationships that led to intimate social intercourse with New York City.

3.4. Diffusion to New OrLEans. Though the city of New Orleans is located in the southern United States, it has long been recognized that its dialect is quite different from other cities in the Southern States. ANAE defines the South as a dialect region by the monophthongization of /ay/ before voiced obstruents, the initiating stage of the Southern Shift. Such monophthongization is found only marginally in New Orleans. There is no trace of the $2^{\text {nd }}$ and $3^{\text {rd }}$ stages of the Southern Shift, which involve the reversal of the relative positions of the short vowels and front upgliding vowels. Still, New Orleans does fall within the larger Southeastern super-region, characterized by the fronting of /ow/ and resistance to the low back merger (ANAE: Map 11.11).

Many observers have noted a resemblance between the speech of New Orleans and that of New York City. For example, Liebling 1961 remarks:

There is a New Orleans city accent. . . associated with downtown New Orleans, particularly with the German and Irish Third Ward, that is hard to distinguish from the accent of Hoboken, Jersey City, and Astoria, Long Island, where the Al Smith inflection, extinct in Manhattan, has taken refuge.

Like most public observers of city dialects, Liebling interprets working-class metropolitan accents as geographic sub-divisions. But the perception of similarity between New York city and New Orleans is based on reality. It is well known that New Orleans has the palatalized form of the $r$-less mid central vowel [әІ] in work, thirty, etc that forms the main stereotype of older New York City speech. Labov 1966 
reports that this stigmatized $\underline{r}$-less feature was rapidly disappearing among younger speakers. However, close attention to the r-colored form used by many New Yorkers today shows a continuing trace of palatalization. Figure 12 displays this phonetic characteristic of New Orleans in two mid-central vowel nuclei as pronounced by one of the oldest ANAE speakers from New Orleans, Sybil P, 69, of German-Italian background. In Figure 12(a) the vowel of first shows a steady state for $101 \mathrm{msec}$, with F2 at about $1373 \mathrm{~Hz}$. F2 then rises abruptly for $44 \mathrm{msec}$ to a peak of $1964 \mathrm{~Hz}$. At the same time it comes into close proximity with F3, producing the auditory effect of a palatalized [r]. In Figure 12(b), a similar pattern is followed in the first syllable of person, though the conjunction of F2 and F3 is not maintained as long.

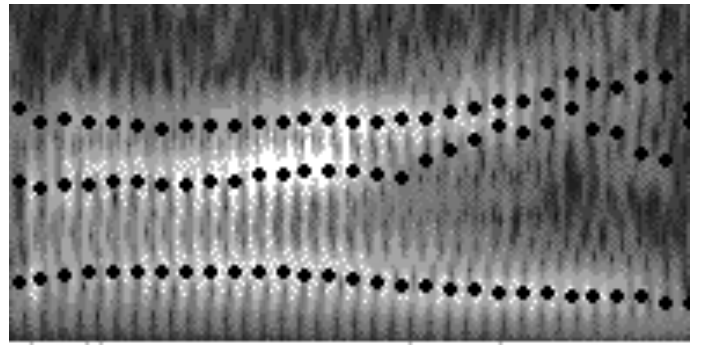

(a)

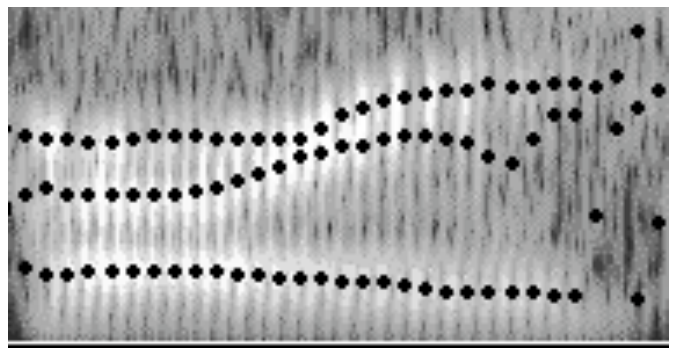

(b)

FIGURE 12. LPC analysis of pronunciation of vowel nuclei of (a) first and (b) pers(on) by Sybil P., 69 [1996], New Orleans LA, TS611.

A palatalized mid-central vowel is also characteristic of areas of South Carolina and eastern Georgia (Kurath and McDavid 1961), and can be found in the Gulf states (Pederson et al 1986). In New Orleans, it appears in conjunction with many Northern phonetic features. One phonetic characteristic rarely found in the South is the use of stops for interdental fricatives, widely recognized as a feature of New York City working class speech. ${ }^{26}$ Sybil P. uses initial stops in Thursday and thirties. (It should be noted that Sybil P. had worked as a secretary in a bank and cannot be considered a lower-class speaker.)

When we turn to the short-a system, the parallels between New Orleans and New York City are even more striking. Figure 13 displays the short-a distribution of Sybil P. Again, the solid triangles and empty squares superimpose the NYC system on the New Orleans system, so that similarities and differences are immediately 
visible. A diagonal line separates the tokens heard as tense from those heard as lax. Three black triangles appear in the lax distribution: Dan, grandparents, after. ${ }^{27}$ In the tense distribution we find short- $a$ before nasals, voiced stops /b/ and /d/ (bad, sad, crab, Crabtree), and voiceless fricatives (asked, basketball, last). The general constraint excluding function words is absent: has, have and had are all tense. This also suggests that as in Cincinnati, the distribution has been generalized to include voiced fricatives $/ \mathrm{z} /$ and $/ \mathrm{v} /$. On the other hand, the constraint against tensing in open syllables is present here, as shown in lax mammal, planet, travel, traffic.

New Orleans displays another feature that is uncommon in the South: the raising of /oh/ in law, cost, hawk, etc. to mid back and lower high position. ANAE (Ch. 18.4) shows that for most Southern speakers, the nucleus of /oh/ is in the same position as /o/ in cot, rock, etc. and is distinguished by a back upglide. Outside of New Orleans, raised /oh/ of this type is found in a continuous belt of East Coast cities ranging from southeastern Connecticut to New York (and Albany), Philadelphia and Baltimore. Figure 13 also shows the clear separation of /o/ and /oh/. The mean F1 of /oh/ is $677 \mathrm{~Hz}$, comparable to the raised /oh/ of the Mid-Atlantic States, defined by the criterion $\mathrm{F} 1(\mathrm{oh})<700$. 


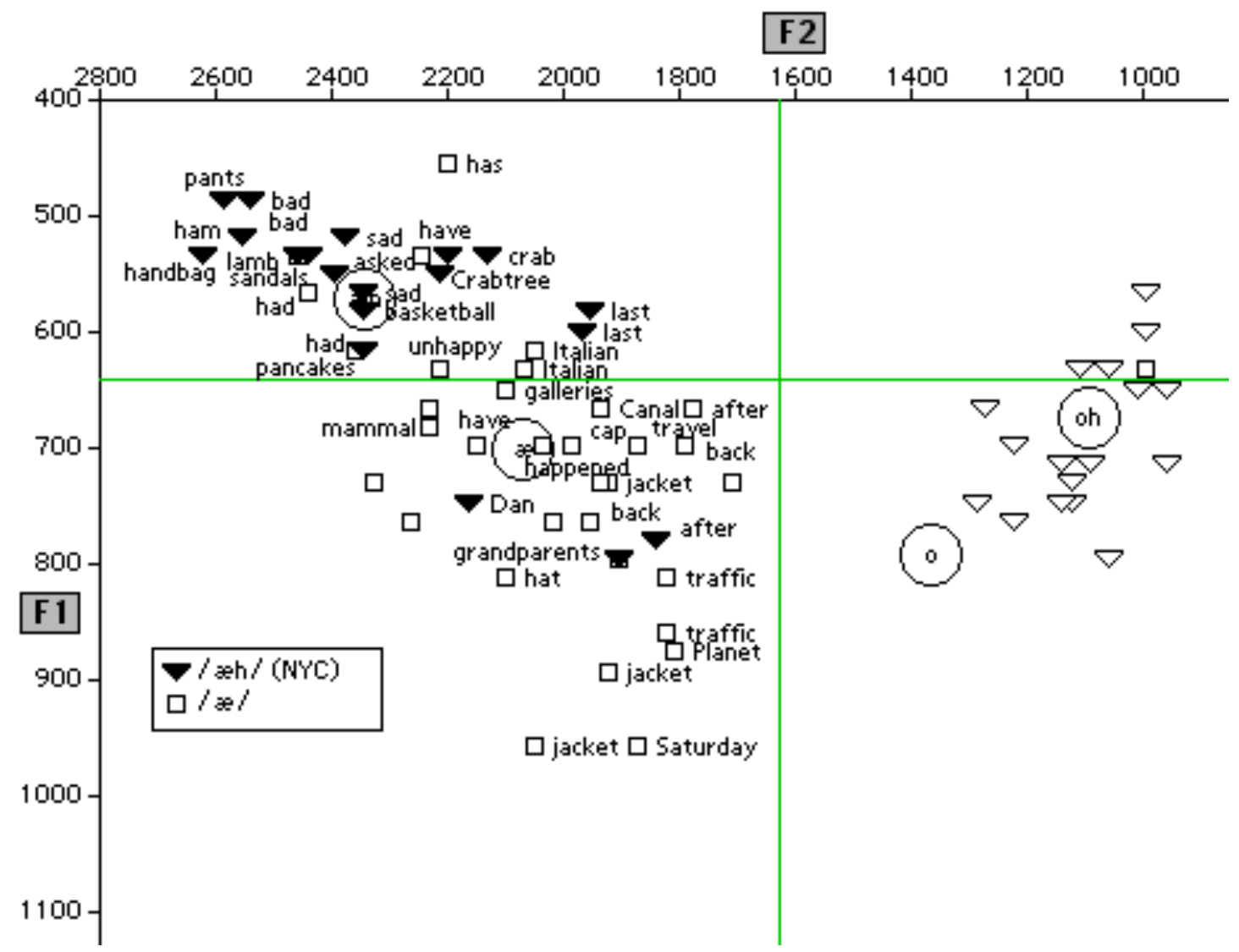

FIGURE 13. Short- $a$ distribution of Sybil P., 69 [1996], New Orleans LA, TS611.

A younger New Orleans ANAE subject is Elizabeth G, who was 38 years old when interviewed in $1996 .^{28}$ Again, the distribution of tense vowels matches the NYC system, including short- $a$ before nasals, voiced stops (dad, bad, sad, grabbing) and voiceless fricatives (ask, grass, glass, master, past). Again the class of function words is tense, and not lax (have). The status of the open syllable constraint is severely weakened. The word internationally is clearly tense, and ceramic is in an intermediate position. On the other hand, Canada and catholic are clearly in the lax set.

As further evidence of the weakness of the open syllable constraint in New Orleans, one may consider the speech of Dr. John (Mac Rebennack), a prominent representative of New Orleans musical tradition who grew up in the Third Ward of the city at mid-century. In a broadcast of March 16, 2005, Dr. John showed the following pattern of tense and lax short- $a .^{29}$ 
Tense [closed syllable] answer, fancy, hand, bad, dad

Tense [open syllable] piano (2), classical, daddy, fascinate [2], Manny

Lax [closed syllable] that, cats, fact, that's, at

Lax [open syllable]

$\underline{\text { Allen }}$

Dr. John's tensing pattern includes nasals, voiced stops and voiceless fricatives, as in New York City, but open syllable words are treated in the same way as closed syllables.

In New Orleans, as in Cincinnati, the local pattern is receding. Two other New Orleans speakers analyzed acoustically are 38 and 44 years old; both show the nasal short- $a$ system, as in other Louisiana cities, Shreveport and Baton Rouge.

The history of New Orleans points to repeated and extensive connections with New York City. While Cincinnati was an industrial rival of New York in the middle of the $19^{\text {th }}$ century, the city of New Orleans had intimate and complementary relations, as the port of shipment for the cotton trade financed by New York bankers. This aspect of the history of New Orleans is described by McNabb and Madère (Ch. $3: 1)$.

From 1803 until 1861, New Orleans' population increased from 8,000 to nearly 170,000 . . By 1830 , New Orleans was America's third largest city, behind New York and Baltimore. . . During the Pre-Civil War period, a scarcity of capital in New Orleans forced seekers of large-scale investment to look to New York, London, or Paris.

Berger 1980 summarizes the evidence for close relations between New Orleans and NYC in the middle of the $19^{\text {th }}$ century.

In the ante-bellum period, roughly between 1820 and 1860 , financial, commercial and social relations between the city and the South were at fever pitch: New York banks underwrote the plantation economy, cotton was shipped routinely from New Orleans, Charleston, Savannah and Mobile to be trans-shipped to England, and Southern planters regularly combined business with pleasure in the Big Apple of the 1800s'. --p. 137.

Berger 1980 cites the judgment of Foner 1941 as to the predominance of New York City in New Orleans (p. 137): 
Down to the outbreak of the Civil War, New York dominated every single phase of the cotton trade from plantation to market.

Berger's aim was to buttress the case for the derivation of the NYC palatalized mid-central vowel from New Orleans; this is the opposite direction of influence than the one proposed here for the short-a pattern. ${ }^{30}$ The gravity model and the historical facts argue for a greater direction of influence from the larger city. We find many descriptions of commercial and social relations between New Orleans and New York in the five-volume history of The Older Merchants of New York City by John Scoville (1885); the typical pattern involves movement of New Yorkers to New Orleans. In Chapter 3 we read that Walter Barrett took a letter of credit for one million dollars to New Orleans by way of Wheeling, hoping to outstrip his competitors in buying up that year's cotton crop (p. 26). It is reported that the founder of the great New York mercantile firm of E. K. Collins \& Son had a house in New Orleans (p. 141). Among the oldest commercial firms of New York City was Brown Brothers \& Co., who established in 1842 a branch in New Orleans under the name of Samuel Nicholson, "who had been many years their clerk (p. 187)". Bradish Johnson, head of the firm of Johnson \& Lazarus, had a brother Henry who was located on a plantation in New Orleans. When Henry died he left the plantation to Bradish, who proceeded to New Orleans and established more favorable conditions for the with 250 slaves, many of whom were able to purchase their own freedom (p. 185). In the description of the prominent Seixas merchant clan, founded by Benjamin Seixas in 1780, we read (Vol II:127): 'Madison [Seixas] is in New Orleans, and a partner in the large firm of Glidden and Seixas.'

Among the bankers closely related to New Orleans were many representatives of the large Sephardic Jewish families (Lazarus, Seixas). Scoville underlines the importance of the Jews in many places: 'The Israelite merchants were few then [1790], but now? they have increased in this city beyond any comparison. There are 80,000 Israelites in the city. It is the high standard of excellence of the old Israelite merchants of 1800 that has made this race occupy the proud position it does now in this city.' (p. 127). We can see how intimate the relations were between the Jewish population of the two cities by examining Korn's history The Early Jews of New 
Orleans, which deals with social and business relations from 1718 to 1812 .

References to New York City are found on 55 pages, more than any other city. ${ }^{31}$

Following the publication of ANAE, I received a letter from Mr. Herman S.

Kohlmeyer, Jr, Senior Vice-President of the investment firm A. G. Edwards, who described himself as "the last person in New Orleans who still makes his living from the cotton trade." His account leaves no doubt that Jewish merchants with strong New York City connections played a formative role in the upper class speech of New Orleans.

I am the great-grandson of some of our top cotton merchants. . . as is my closest friend. They were all German Jewish immigrants who came over in the 1830-1860 era. . . I remember very well friends of my father's generation who talked about how hard they "woiked" before they went home to their house on "Foist" Street. That was very much our upper class speech, as much with the Christians and with the Jews. ${ }^{32}$

The detailed linguistic resemblances between New York City and New Orleans involve both of the pivot points that have been found to determine the main directions of development of North American dialects: the status of short-o as an integral phoneme distinct from long open-o and the status of short-a (Labov 1991). As in New York, the New Orleans raised /oh/ insures the separate status of short-o as the phoneme $/ \mathrm{o} / .^{33}$ As in New York, New Orleans divides short- $a$ into two distinct classes, separating tense vowels before front nasals, voiced stops and fricatives in closed syllables from voiceless stops and liquids. However, the New Orleans adaptation is only superficially similar to the NYC configuration: it is a phonetically conditioned set of allophones rather than a grammatically and lexically specified distribution.

In the four cases of diffusion of the NYC short- $a$ pattern presented above, phonetic conditioning by the following segment is the common thread, though the phonetic pattern is not perfectly transmitted. The voiced velars are excepted from the voiced stops, and tensing before voiceless fricatives is sometimes generalized to voiced fricatives. But the most regular differences are found at a more abstract level. The function word constraint is lost: with few exceptions, can, am, and, have, has, had are tense, though they are always lax in NYC. The second major difference is the 
loss of the constraint against tensing in open syllables, quite general though not complete in New Orleans. It might seem at first glance that this represents the loss of a phonological constraint. But on reflection it may be seen as the loss of the effect of inflectional boundaries in closing the syllable. When short-a is tensed in all open syllables, there is no longer a difference between [Cardinal] _mænin/ and /mæhn\#in/ [the pumps], or between monomorphemic /bænər/and /bæhn\#/or/, a person who bans. The adults who adopted the NYC system did not observe that tense /mæhn\#in/, /bæhn\#ər/, /pæhs\#in/, /pæhs\#ər/ were bimorphemic, while /mæniN/, /bænər/, /kæsəl/, /bæfəl/ are not. Accordingly, they generalized the tensing of bimorphemic to all words of this phonetic shape. This is consistent with the proposition that the main agents in diffusion are adults who are less likely to observe and replicate abstract features of language structure.

\subsection{DifFUSION ACROSS COMMUNAL GROUPS. The discussion so far has} concerned the diffusion of linguistic structures from place to place. The speech communities described so far-New York, Albany, Cincinnati, New Orleans - are formed by the population defined in American society as the white mainstream. They are geographical unities, differentiated internally by social class, but separated sharply from the African-American and Latino populations in the same cities. Most American cities include three major communal groups, in the sense defined in Blanc's 1964 study of the Muslim, Christian and Jewish dialects of Baghdad. Contacts between such communal groups are primarily among adults, and when linguistic patterns diffuse from one group to the other we can expect the same loss of structure that was observed in geographic diffusion.

This is a major topic to be explored in relation to the many studies of African American and Latino dialects in the United States. One example can be cited here, from Henderson's 1996 study of short-a in the African American community of Philadelphia. As indicated above, the Philadelphia short-a distribution into tense and lax classes is similar to that of New York City in the presence of grammatical conditioning and the open syllable constraint. Among the features in which it differs are (1) before voiced stops, only three words are tense ( $\underline{\mathrm{mad}}, \underline{\mathrm{bad}}, \mathrm{glad})$, and (2) 
before nasals, irregular verbs are lax ( $\underline{\operatorname{ran}}, \underline{\text { swam, began }}){ }^{34}$ Table 1 compares short-a tensing for the spontaneous speech of 100 white Philadelphians reported in Labov 1989 with the 30 speakers of Henderson's study.

For the normally tense classes, the white Philadelphians are close to $100 \%$. African-Americans are equivalent in tensing before nasals, come close for the mad, bad, glad sub-class, but fall considerably short for short-a before voiceless fricatives in path, bath, pass, etc., with only $69 \%$ tense. Although there is some lexical diffusion in open syllables, white Philadelphians show only $0.4 \%$ tensing overall. The open syllable constraint is very much weaker among African-Americans; almost half of he tokens are tense. Finally, one can observe that the grammatical constraint that laxes irregular verbs ending in nasals is almost missing in diffusion to the African American community: only $29 \%$ are lax as compared with $80.7 \%$ lax among white Philadelphians. This loss of structural detail in diffusion across communal groups echoes the patterns of geographic diffusion where contact is largely through adult speakers.

Table 1. Tensing of short- $a$ for Whites and African-Americans in Philadelphia.

$\begin{array}{cc}\text { Euro-Americans } & \text { African-Americans } \\ \text { [Labov 1989] } & \text { [Henderson 1996] } \\ \% \text { Tense } & \% \text { Tense }\end{array}$

Following segment

before voiceless fricatives

98

69

$\underline{\mathrm{mad}}, \underline{\text { bad, }}$ glad

99

83

Normally lax in white Philadelphia dialect before intervocalic nasals 


\subsection{THE TRANSMISSION AND DIFFUSION OF MERGERS AND SPLITS. The} argument so far has not considered the type of structural diffusion that is most frequent and most prominent in historical linguistics and dialectology: mergers. Herzog's corollary of Garde's principle (Herzog 1965, Labov 1994) states that mergers expand geographically at the expense of distinctions; there is massive empirical evidence of such expansion. ${ }^{35}$ Though the adoption of a merger is not conventionally considered to be structural borrowing, it must be considered so, since the recipient dialect loses one of its categories in adopting the structure of the expanding dialect. Up to this point, we have been arguing that adults do not easily acquire new structural categories, but the evidence does not so far bear on the loss of a category.

Herold's (1990) proposal for the diffusion of a merger is that speakers of a two-phoneme system in contact with a one-phoneme system find that the contrast is not useful and so cease to attend to it. There is ample evidence that merger in perception precedes merger in production (Di Paolo 1988, ANAE Ch. 9) and nearmergers give us a static view of such a situation (Labov 1994, Ch. 12, Labov et al. 1992). But this does not tell us how a merger in the speaker's perception is transmitted to the speaker's children. There are indeed numerous cases of a contrast strongly maintained among adults but solidly merged in the speech of their children, but the mechanism of such transmission is still obscure. ${ }^{36}$ It is possible that adults come to lose the distinction in production as well. However, none of the real-time panel studies - re-studies of the same individuals over their life span — have dealt with ongoing mergers that would produce evidence of adults collapsing phonemic categories during their lifetimes (Cedergren 1988, Trudgill 1988, Sankoff 2002).

Until more evidence on the diffusion of mergers is acquired, our discussion of limitations on adult language learning must be focused on the acquisition of new grammatical constraints. In rule-based generative systems, this may refer to the acquisition of a rule that operates within the phonological cycle. In constraint-based systems, it means raising the ranking of a grammatically defined constraint over the ranking of a phonetically defined constraint. 
The continuity of the New York City short-a system from 1896 to the present and the uniformity of the Mid-Atlantic short-a system in Philadelphia, Reading, Wilmington and Baltimore all indicate that such patterns can be faithfully transmitted across generations through children's language learning abilities. However, there is evidence that a pattern of this complexity cannot be learned as a second dialect, even by children. Payne studied the acquisition of the Philadelphia dialect by children of out-of-state parents in King of Prussia $(1976,1980)$. She found that children under 10 years of age acquired the phonetic variables of the Philadelphia system after only a few years in King of Prussia, but only 1 of 34 children of out-of-state parents acquired the lexical and grammatical conditioning of the short-a system. There were however differences in the degrees of approximation, depending on the parents' dialect (Payne 1976, Labov 1994). Children of New York City parents approximated the Philadelphia system much better in identifying the three lexical items mad, bad, glad as the only tense vowels before voiced stops than in acquiring the general Philadelphia rule that short- $a$ is always lax before back consonants (cash, rash, smash, etc.). Children of parents from regions with allophonic short-a distributions of type (a-c) above showed the opposite bias, favoring phonetic generalization. This strongly suggests that the NYC families had acquired their own short-a pattern as a lexical list rather than as a rule-governed distribution. If we conclude that the NYC short-a distribution is a phonemic split, it does not lead to the conclusion that it diffuses as a phonemic split. What we have seen in North Plainfield, Albany, Cincinnati and New Orleans is the diffusion of a close approximation to the segmental conditioning of the NYC system, without its lexical, grammatical or syllabic conditioning. In other words, adults with allophonic short-a systems of types (a-d) will approximate the NYC pattern as a rule or constraint system of the type they have acquired as children.

This conclusion is consistent with the fact that the distinction between transmission and diffusion is maximal in the case of splits. The converse of Garde's Principle is that splits are rarely reversed. Britain's (1997) account of the complexities of the $/ \mathrm{u}-\Lambda /$ split in the Fens shows the irregular result of a rare case of expansion of the split where the two-phoneme system is favored by social prestige. The constraint on learning a new phonemic contrast applies to equally to studies of 
the children of inmigrant parents. Trudgill examined the ability of 20 adults born in Norwich to reproduce the local distinction between the vowel classes of own [ $\mathrm{uun}$ ] and goal [gu:1]. Ten whose parents were born in Norwich did so; the ten whose parents were born elsewhere could not (Trudgill 1986:35-6).

It is apparent that an unbroken sequence of parent-to-child transmission is required to maintain complex patterns of phonetic, grammatical and lexical specification like the NYC short-a pattern. Therefore, if speakers from other dialect areas enter the community in large numbers, their children will dilute the uniformity of the original pattern. Although the Mid-Atlantic dialects are quite stable, there is some indication of such a weakening. Lexical diffusion of open syllable words before /n/ has been traced since 1980 (Labov 1989, Roberts and Labov 1995); some neighborhoods report general tensing before /1/ (Banuazizi and Lipson 1998); still other neighborhoods show shifting to the default nasal system, as in certain small towns of southern New Jersey (Ash 2002).

To examine more closely the difference between transmission by children and diffusion by adults, we turn to a complex system which is free of such lexical and grammatical specification, the Northern Cities Shift. The structural complexity involved here has to do with the intricate interrelations of vowels as they evolve in chain shifts within and across sub-systems (Martinet 1955, Moulton 1960).

\section{Diffusion of the Northern Cities Shift. The Northern Cities Shift} [NCS] is the rotation of six vowels shown in Figure 14 (Labov, Yaeger and Steiner 1972, Labov 1991, Eckert 1988, 1999, ANAE Ch 14, Gordon 2001). The NCS was initiated by the general tensing and raising of all short- $a$ words to mid and high position. The absence of vowel tokens in low front position then led to a shift of two neighboring vowel classes into that vacant space: short- $o$ shifted frontward and short$e$ shifted downward. This was followed by the lowering and fronting of long open-o. In later developments, short-e shifted back towards $/ \Lambda /$, and $/ \Lambda /$ moved back to the position formerly occupied by long open-o (/oh/), while /i/ moved down and back. The NCS develops incrementally in all cities of the Inland North, including Syracuse, 
Rochester, Buffalo, Cleveland, Toledo, Detroit, Flint, Grand Rapids, Kalamazoo, Gary, Chicago, Kenosha, Milwaukee and Madison. The most remarkable fact about the NCS is its uniform distribution across the vast area surrounding the Great Lakes (ANAE Chs. 11, 14).

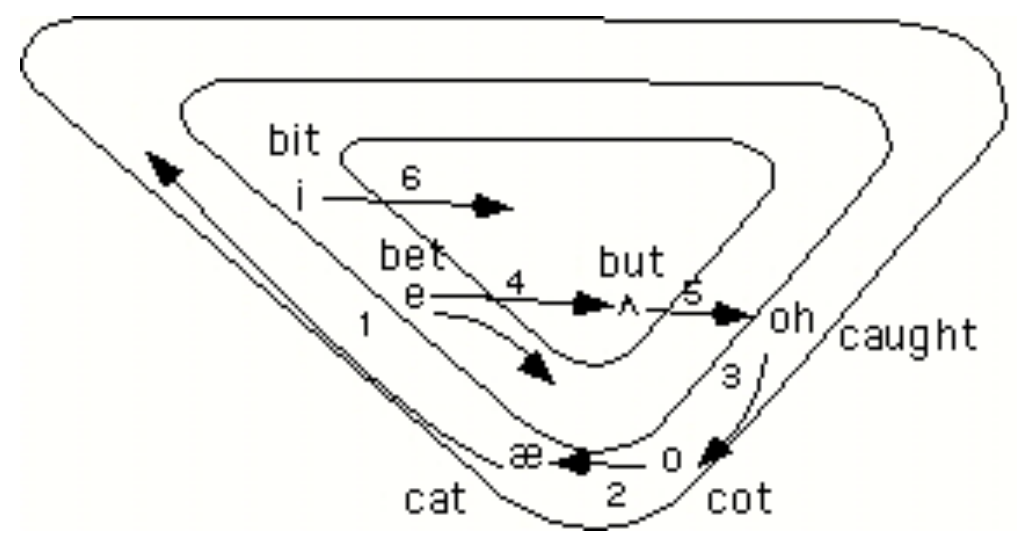

FIGURE 14. The Northern Cities Shift.

Figure 15 shows how the NCS is realized in the vowel system of Kitty R. of Chicago when she was interviewed at the age of 56 when she was interviewed in 1993. The general raising of /æ/ to upper mid position is shown by the solid black squares, and the fronting of /o/ by the small empty squares with five tokens well front of center. Diamonds indicate the backing of /e/ with an F2 of $1864 \mathrm{~Hz}$, only $320 \mathrm{~Hz}$ higher than the F2 of /o/ $(1544 \mathrm{~Hz})$. Wedge is shifted well to the back, overlapping /oh/ which has not lowered extensively. 


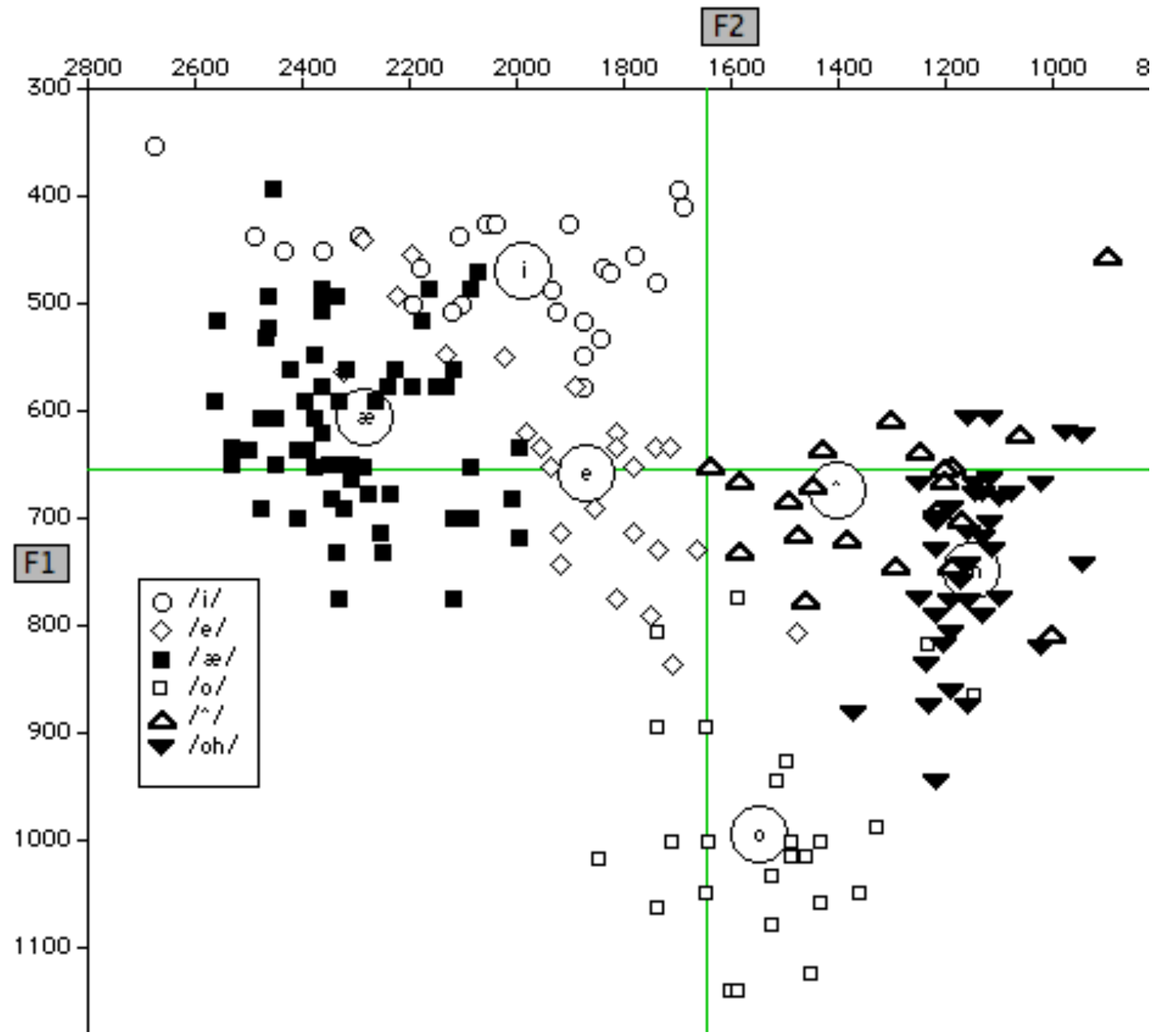

FIGURE 15. The Northern Cities Shift in the vowel system of Kitty R., 56 [1993], Chicago IL, TS 66.

Figure 16 displays the geographic distribution of the Northern Cities Shift. Since the NCS is a complex rotation of its elements, the measurement of any one vowel tells us little about the progress of the shift. ANAE relies on structural relations among NCS vowels to map the progress of the shift. One such criterion is the combined effect of stages 2 and 4 of the NCS (Figure 14), measuring the extent to

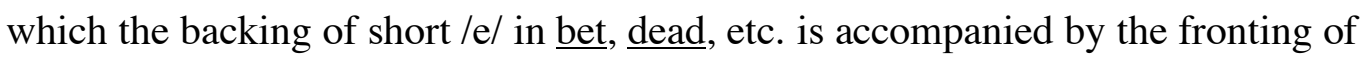
short /o/ in cot, odd, etc. For most North American dialects, /e/ is a front vowel and /o/ is a back vowel, with mean differences in F2 of about $1000 \mathrm{~Hz}$. For speakers most fully engaged in the NCS, /e/ is close to or aligned with /o/ along the front-back dimension. In Figure 16, the grey circles indicate speakers who satisfy the ED criterion, for whom the difference between the mean F2 of /e/ and the mean F2 of /o/ 


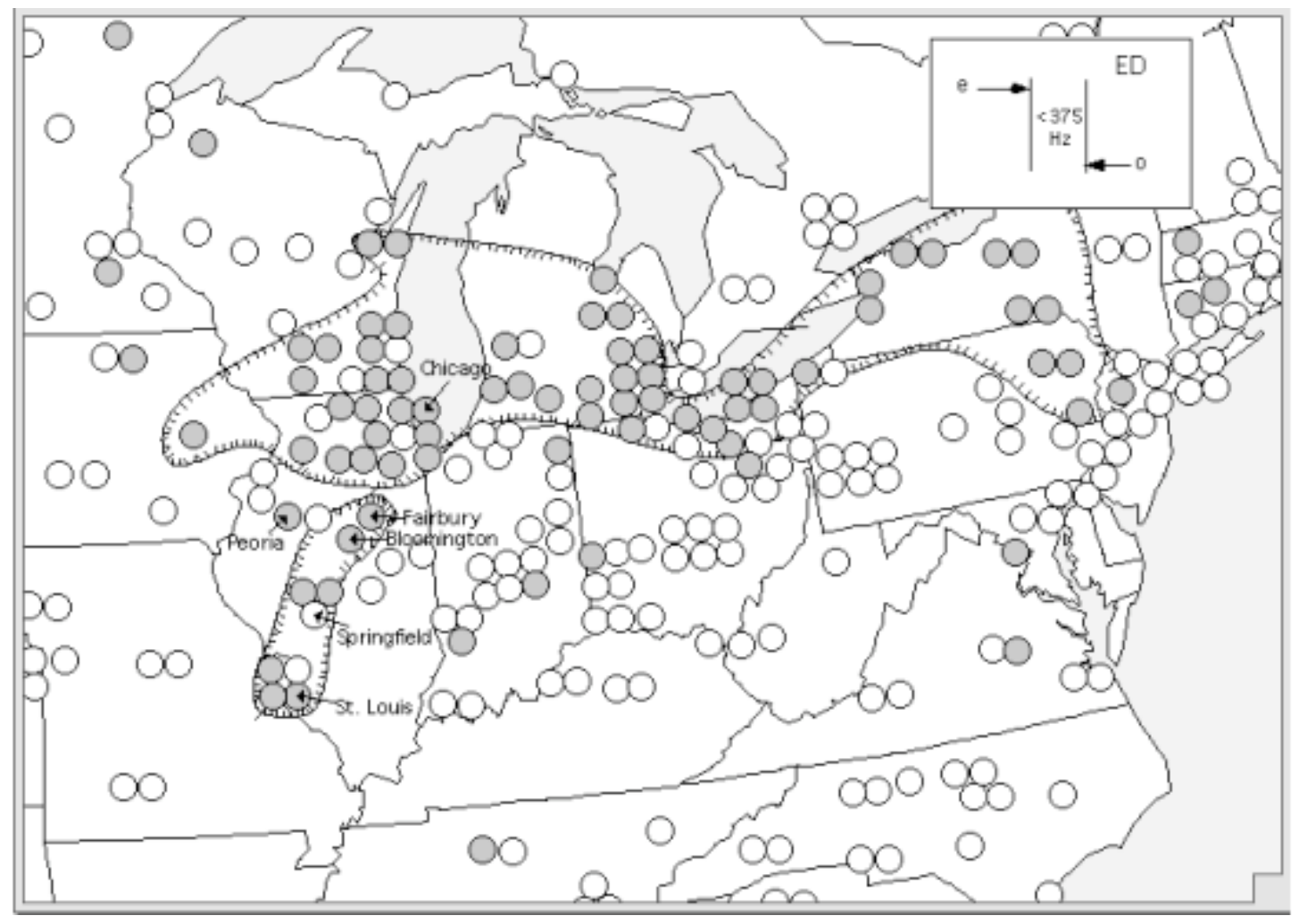

FIGURE 16. The ED measure of the advance of the Northern Cities Shift: in the Inland North and the St. Louis corridor Grey symbols = F2(e) - F2(o) $<375$ Hz.

is less than $375 \mathrm{~Hz}$. The Inland North-the region in which the NCS is operating--is delineated by this measure.

The earliest records we have of the chain shift of /æ/, /o/ and /oh/ date from the 1960s. Yet there is reason to think that the initiating event of the NCS took place a hundred years earlier with the construction of the Erie Canal in Western New York State. A koinéization of various complex short-a systems to the simple general tensing seems to have occurred when workers and migrants from all over the northeast were integrated into the rapidly expanding cities of Rochester, Syracuse and Buffalo (Labov 2004). The unrounding and centralization of /o/ had already taken place in Western New England (ANAE Ch. 16). With westward migration of entire communities, the conditions for the chain shift were transmitted faithfully across the Inland North as far as Wisconsin.

The linguistic boundary separating the Inland North from Midland vowel patterns is the sharpest and deepest division in North American phonology. The 
isogloss bundle that separates these two areas is the southern limit combines six measures of the progress of the NCS, the southern limit of Canadian raising of /ay/ and the southern limit of dialects with /aw/ backer than /ay/ (ANAE Ch. 11). Figure 16 shows that the front-back approximation of /e/ and /o/ is generally absent in the Midland region, except for St. Louis and nearby communities. The city of St. Louis, located squarely in Midland territory, has recently developed many of the elements of the NCS. St. This city has long been known to display a mixture of Northern, Midland, and Southern features (Murray 1993, 2002) but recent decades have witnessed a strong shift to Northern phonology. The characteristic St. Louis merger of /ahr/ and /ohr/ in are and or, card and cord, barn and born, etc., has all but disappeared among younger speakers, who display instead the general merger of or and ore, cord and cored, along with a clear separation of this class from /ahr/ in are and card.

Figure 17 shows both the modern St. Louis vowel pattern and the traditional merger before / $\mathrm{r}$ / in the system of Marvin H., interviewed in 1994 at the age of $48 .{ }^{37}$ At upper right, one can see tightly clustered the traditional /ohr/ class - $\underline{\text { hoarse, four, }}$

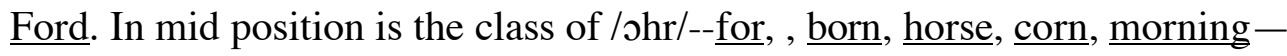
alongside /ahr/ in part, far, and barn. The distinction of hoarse and horse, four and for is well illustrated, as well as the identity of far and for, born and barn. At the same time, the distribution of the NCS vowels matches the Chicago pattern of Figure 15 quite well. All /æ/ are raised to mid position, /o/ is well fronted and /e/ is backed close to the midline. The difference between the second formants of /e/ and /o/ is only 134 Hz. Wedge is moderately back and some tokens of /oh/ are quite low. It is apparent that Marvin H. has combined the traditional St. Louis pattern with the Northern Cities Shift. 


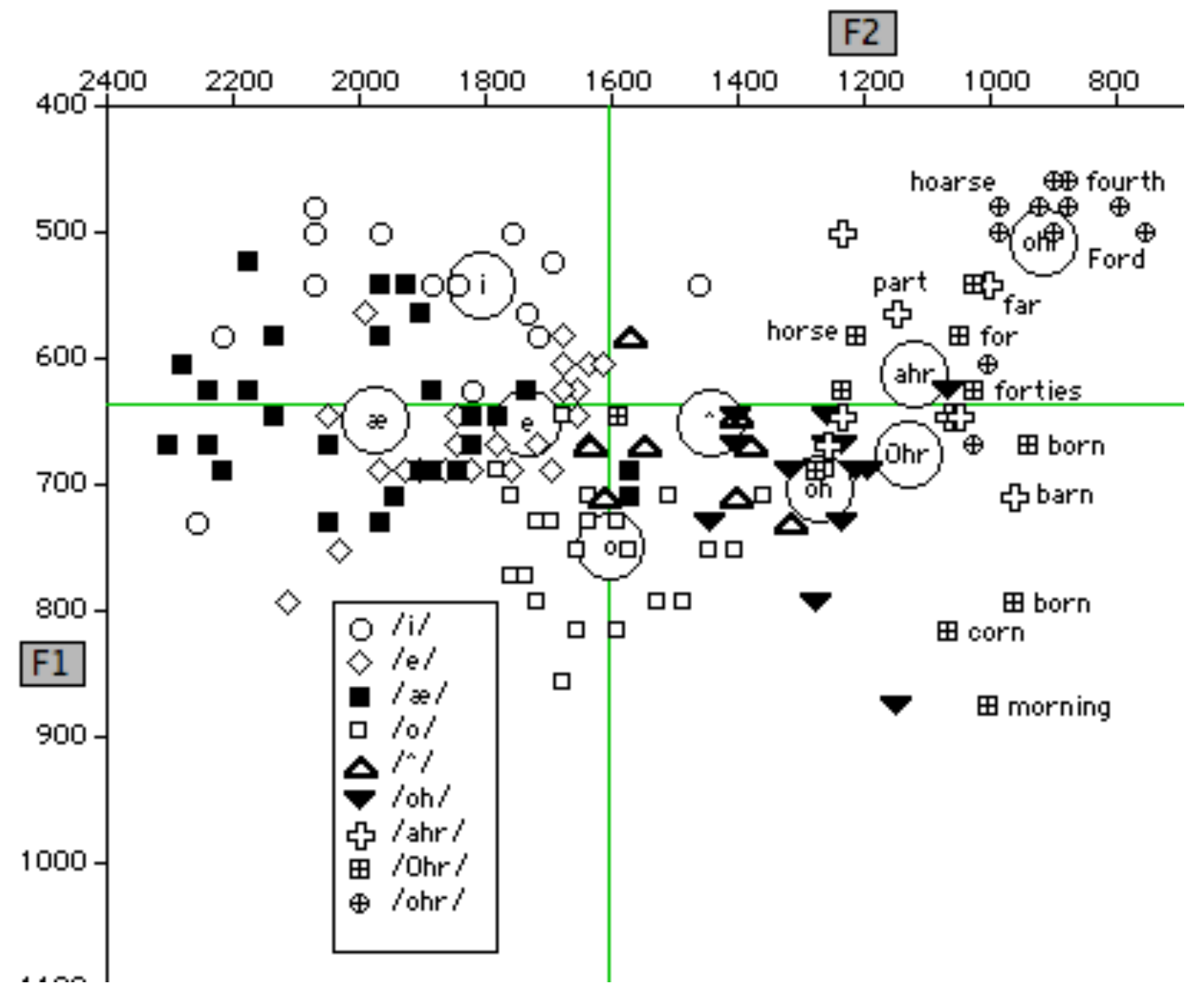

FIGURE 17. Northern Cities Shift and merger of /ohr/ and /ahr/ for Martin H., 48 [1994]. St. Louis MO, TS 111. On this chart, /Ohr/ =/ohr/.

This recent development in St. Louis is not an independent phenomenon, distinct from the chain shift in the Inland North. Many ANAE maps show diffusion of NCS features along a narrow corridor extending from Chicago to St. Louis along Route I-55 (Figure 18). ${ }^{38}$ The ANAE data for this corridor is based on speakers from three cities along the interstate highway (Fairbury, Bloomington, Springfield), along with four speakers from St. Louis. ${ }^{39}$ 


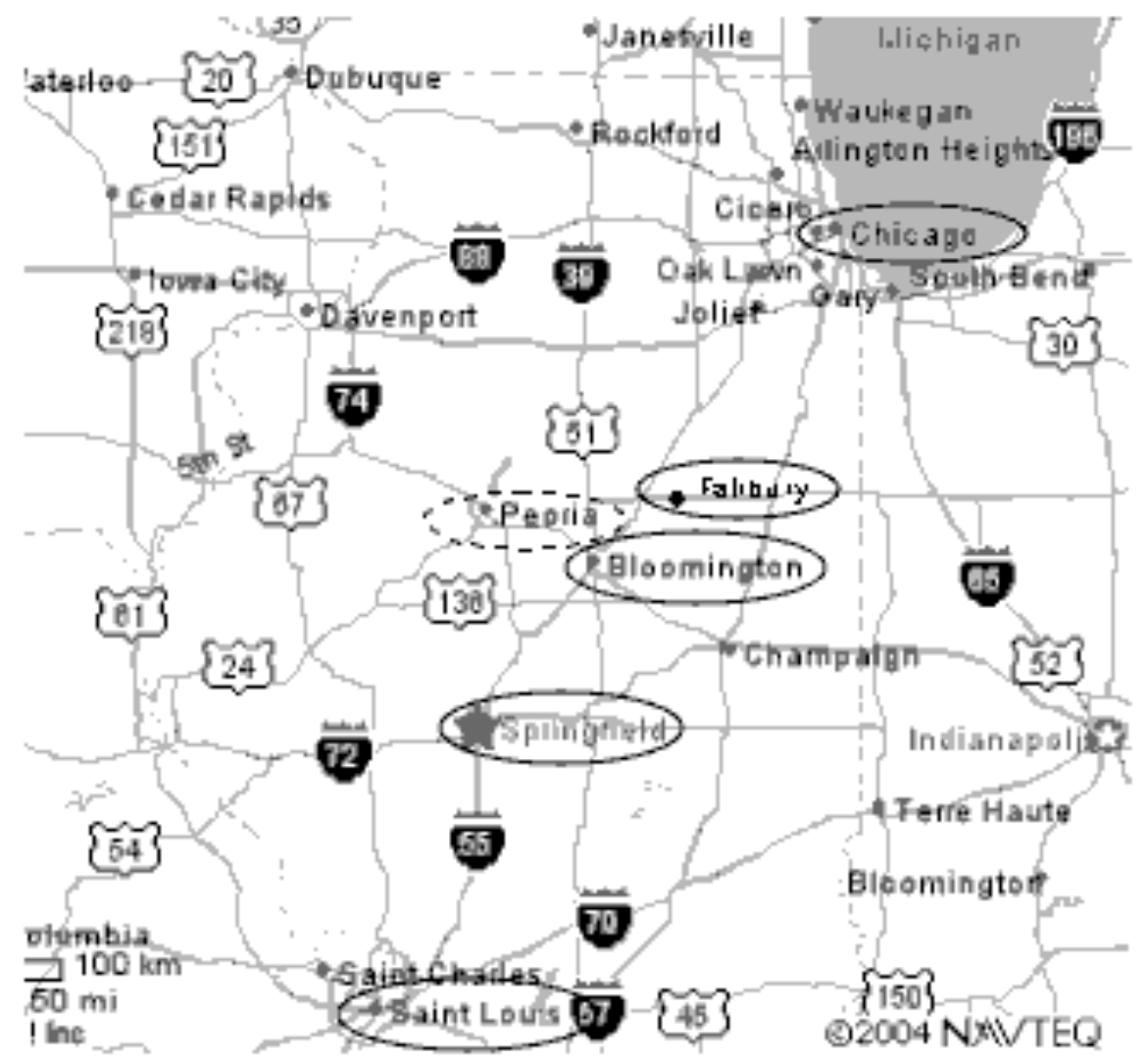

In

FIGURE 18. The corridor along Route I-55 from St. Louis to Chicago.

In Figure 16, 59 of the 67 speakers within the isogloss satisfy the ED criterion, a homogeneity of .88. A similar proportion of speakers in the St. Louis corridor do so -7 out of 9 .

A second measure, displayed in Figure 19, shows even more clearly how the St. Louis corridor is differentiated from its Midland neighbors. Stage 2 of the NCS, the fronting of $/ \mathrm{o} /$ and stage 5 , the backing of $/ \Lambda /$, has the effect of reversing the relative front-back positions of these two vowels as compared with neighboring dialects. The "UD criterion" used by ANAE to define the progress of the NCS defines the speakers involved in this chain shift as those for whom $/ \Lambda$ is further back than $/ \mathrm{O} /$ (grey circles on Figure 19). Of all measures of the progress of the NCS, this yields the sharpest differentiation between the Inland North and the Midland. Homogeneity within the Inland North is even greater than for the ED measure: 65 out of 67 subjects in the Inland North satisfy the UD criterion, or .94. The almost total absence of grey 
symbols in the Midland area of Figure 15 contrasts with the 5 grey symbols in the St. Louis corridor. Though this corridor is represented in ANAE by only four cities and nine speakers, the probability of the occurrence of this feature in the corridor by chance is less than 1 out of $1000 .^{40}$ On the other hand, it is significantly less frequent than in the Inland North: only five of the nine speakers in the St. Louis corridor are marked with grey symbols. ${ }^{41}$

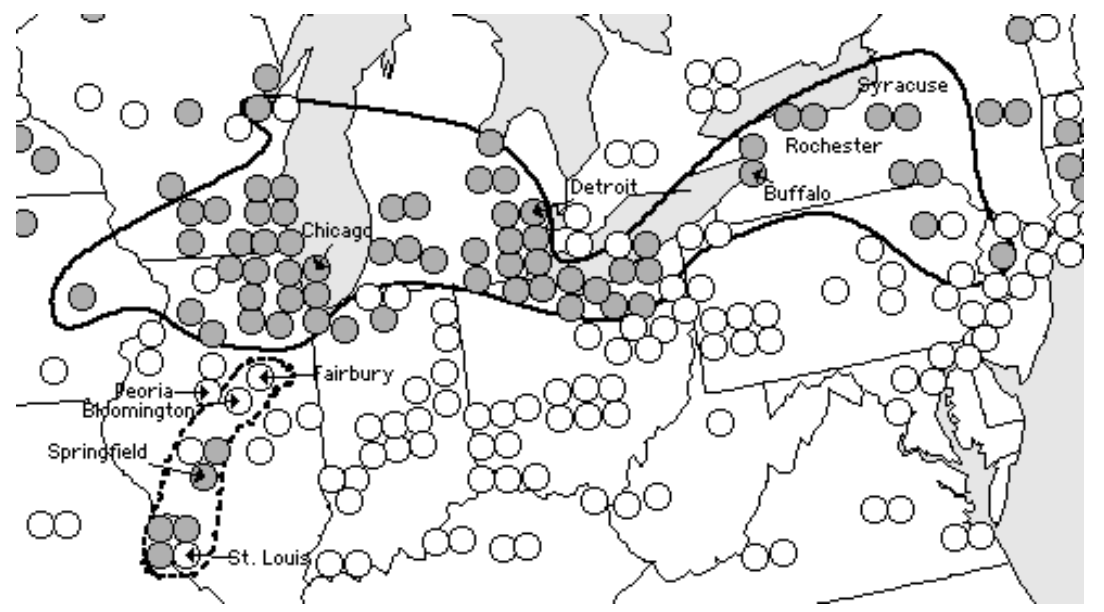

FIGURE 19. The UD measure of the advance of the Northern Cities Shift in the Inland North and the St. Louis corridor [grey symbols $=$ UD measure: F2 $(\Lambda)<F 2(0)$. Solid isogloss $=$ the Inland North as defined by the ED measure].

Figures 16 and 19 illustrate the diffusion of the NCS along I-55 from Chicago to St. Louis. However, it appears that the NCS along this corridor is not the same linguistic phenomenon as in the Inland North itself; there is reason to believe that the systematic chain shift mechanism, triggered by the general raising of short- $a$, is not driving the shift in the St. Louis corridor.

Figure 20 is a map of the same region displaying speakers for whom the NCS is complete--who show all relevant criteria. In addition to the ED and UD criteria, we have:

AE1: general raising of /æ/ in non-nasal environments, $\mathrm{F} 1(\mathfrak{x})<700 \mathrm{~Hz}$.

O2: fronting of /o/ to center, F2(o) $<1500 \mathrm{~Hz}$.

EQ: The reversal of the relative height and fronting of /e/ and /æ/:

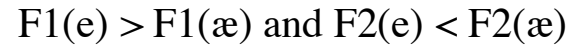


Figure 20 shows that only 28 of the 67 Inland North speakers meet this strict criterion $-42 \%$. Sixteen of the 28 are in the largest cities: Detroit, Rochester, Syracuse, Chicago. On the other hand, the St. Louis corridor shows only one such speaker: Martin H. of Figure 17-and no one else outside of the Inland North

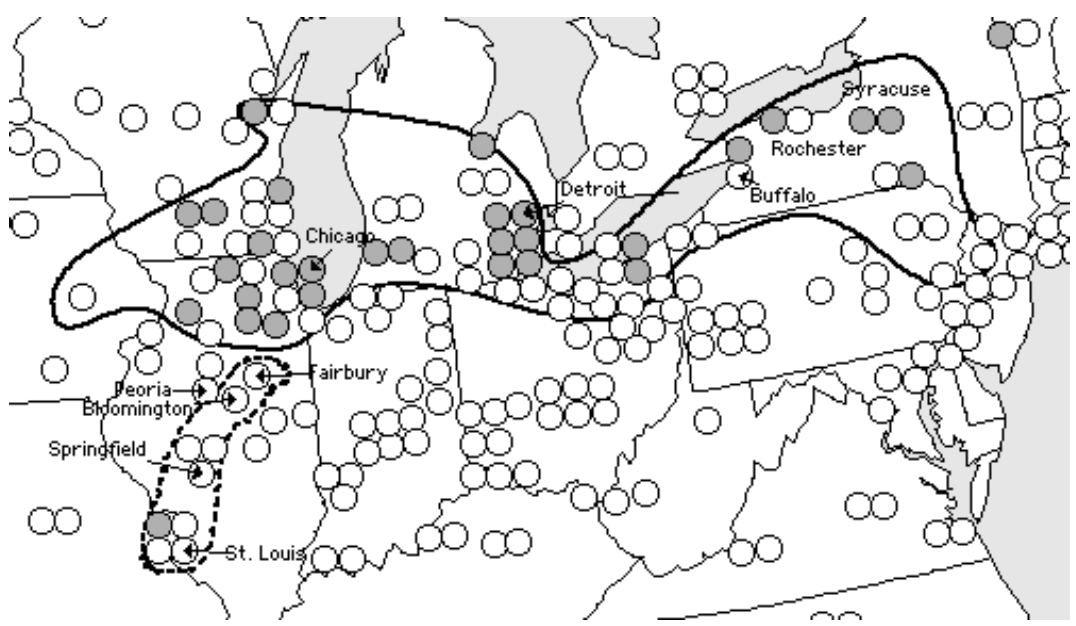

FIGURE 20. Speakers who show all criteria of the Northern Cities Shift: AE1, O2, EQ, ED and UD. Solid isogloss = the Inland North as defined by the ED measure.

The other eight speakers in the St. Louis corridor show an approximation to the NCS rather than the consistent pattern of Figure 19. Five speakers in the corridor meet the AE1 criterion; but only two are marked for O2, and only 1 for EQ. The inference to be drawn from Figure 19 is that the new vowel patterns of St. Louis are not a structural consequence of the general raising of short- $a$, but rather the borrowing of individual elements of the NCS from the Inland North region centered on Chicago.

The geographic distribution of the various stages of the NCS in the Inland North and the St. Louis corridor make it clear that there is much more variation in the corridor. St. Louis speakers are generally in advance of the speakers in the smaller cities along Route I-55. This would not seem much different from the view of diffusion obtained in the Brunlanes peninsula by Trudgill (1974) in Figure 2. In the cascade model displayed there, the change moves from the largest city to the next larger, and so on down, rather than moving steadily across the geographic landscape as in the contagion model (Bailey et al. 1993). But the St. Louis corridor-including St. Louis - is marked by irregularity in both structure and age distribution. 
To the extent that the NCS is the result of the incrementation of sound changes by successive generations of children, we should see a clear relationship between age and the advancement of the shift. The ANAE study of the NCS in the Inland North as a whole shows significant age coefficients at the .01 level for the raising of $/ æ /$, the fronting of /o/, the backing of /e/ and the backing of $/ \Lambda /$ (ANAE Ch. 14). For a close comparison with the nine subjects of the St. Louis corridor, nine speakers from northern Illinois, within the Inland North, are selected in Table 2. Check marks indicate whether a given speaker satisfies the criterion for five systematic measures of the NCS (AE1, O2, EQ, ED, UD). It is apparent that the shift is more advanced in Northern Illinois, but the crucial question is the trajectory of the change in apparent time. In the right hand column, each speaker is ranked for degree of advancement within his or her region by the number of criteria satisfied and this ranking is then correlated with the age of the speaker. While the speakers from Northern Illinois show a sizable r-correlation of .74 with age, a small negative correlation of - 0.21 appears for the St. Louis corridor. A regression coefficient for age on ranking of .08 , significant at the .05 level, is found for Northern Illinois, indicating that a difference of 50 years between two speakers would project to a shift of 4 units in the rankings. No significant regression coefficient is found for the St. Louis corridor.

This result indicates that the advancement of the NCS in the St. Louis corridor is not the result of incrementation by children within the speech community but rather the result of the influence of the Inland North speech pattern on adults. The conversion of the St. Louis system to that of the Inland North may eventually lead to the participation of young children in the process and further incrementation within the community, but the present situation seems to reflect a slower and less regular shift among adults, the result of diffusion along the corridor. 
Table 2. Stages of the Northern Cities Shift found in nine speakers of Northern Illinois and nine speakers in the St. Louis corridor, with ages, rank ordering and correlation of age with rank.

$\begin{array}{lccccccc}\text { Northern Illinois } & \text { AE1 } & \text { O2 } & \text { EQ } & \text { ED } & \text { UD } & \text { Age } & \text { Rank } \\ \text { Sterling IL } & \sqrt{ } & \sqrt{ } & \sqrt{ } & \sqrt{ } & \sqrt{ } & 34 & 1 \\ \text { Elgin IL (1) } & \sqrt{ } & \sqrt{ } & \sqrt{ } & \sqrt{ } & \sqrt{ } & 19 & 1 \\ \text { Elgin IL (2) } & \sqrt{ } & \sqrt{ } & \sqrt{ } & \sqrt{ } & \sqrt{ } & 42 & 1 \\ \text { Joliet IL } & \sqrt{ } & \sqrt{ } & \sqrt{ } & \sqrt{ } & \sqrt{ } & 30 & 1 \\ \text { Rockford IL (1) } & & \sqrt{ } & \sqrt{ } & \sqrt{ } & \sqrt{ } & 37 & 2 \\ \text { Belvidere IL } & \sqrt{ } & & \sqrt{ } & \sqrt{ } & \sqrt{ } & 33 & 2 \\ \text { Hammond IN } & \sqrt{ } & \sqrt{ } & \sqrt{ } & & & 45 & 3 \\ \text { Rockford IL (2) } & \sqrt{ } & & & & \sqrt{ } & 65 & 4 \\ \text { Lena IL } & \sqrt{ } & & & & & 47 & 5 \\ \text { r-correlation } & & & & & & & .74 \\ \text { age coefficient } & & & & & & & .08 *\end{array}$

\section{St. Louis Corridor}

St. Louis MO (1)

$\begin{array}{lllllll}\sqrt{ } & \sqrt{ } & \sqrt{ } & \sqrt{ } & \sqrt{ } & 48 & 1 \\ \sqrt{ } & \sqrt{ } & & \sqrt{ } & \sqrt{ } & 57 & 2 \\ \sqrt{ } & & & \sqrt{ } & \sqrt{ } & 60 & 3\end{array}$

Springfield IL AK

Fairbury IL

$\sqrt{ }$

$25 \quad 4$

Bloomington

$\sqrt{ }$

$27 \quad 4$

Springfield IL (1)

$\sqrt{ }$

$32 \quad 5$

Springfield IL (2)

$\sqrt{ }$

St. Louis MO (3)

$\begin{array}{lll}\sqrt{ } & 67 \quad 5\end{array}$

St. Louis MO (4)

$\sqrt{ } \quad 53 \quad 5$

r-correlation

$\begin{array}{lll}\sqrt{ } & 53 & 5 \\ \sqrt{ } & 38 & 5\end{array}$

age coefficient

$-0.21$

n.s. 
Figure 20 showed that Marvin H. is the only St. Louis ANAE subject speaker to fully represent the NCS. A more characteristic view of how the NCS is realized in St. Louis is seen in Figure 21, from the vowel system of Rose M., the fourth St. Louis speaker of Table $2 .{ }^{42}$ Only one of the NCS movements is vigorously represented: /e/ moves down ( $\underline{\text { bed, }}$ selling) and back ( $\underline{\text { metal, }}$ expensive), There are traces of the other shifts: / $\Lambda$ / has shifted back only to a moderate degree, and as a result, there is considerable overlap between /e/ and $/ \Lambda /$. Two tokens of short-o have moved front of center (pond, hot), but the general /o/ mean - $1405 \mathrm{~Hz}$--is well back of the normalized general F2 mean of $1590 \mathrm{~Hz}$. The most striking deviation from the NCS pattern is /æ/. Instead of a general movement of to upper-mid position, Rose M. shows the nasal system characteristic of the Midland: only the allophones of /æ/ before nasals move to mid front position ( $\underline{\text { dance, }} \underline{\text { dancers, }} \underline{\text { can }}$ ). The majority of the /æ/ tokens remain in low front position, even though a few /o/ tokens cross the center line.

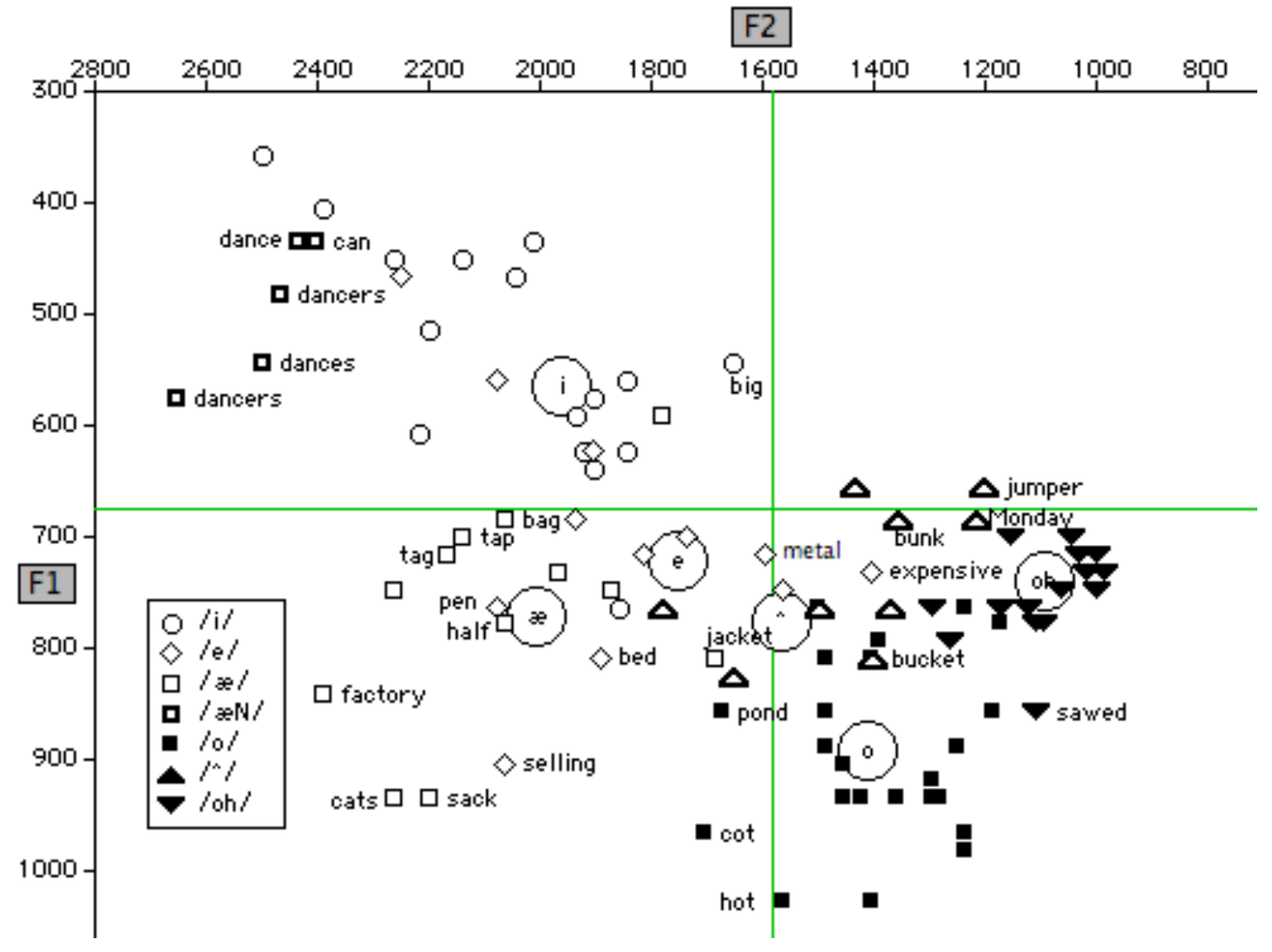

FIGURE 21. NCS vowels of Rose M., 38 [1994], St. Louis MO, TS 161. 
5. THE SOCIAL CONTEXT OF TRANSMISSION AND DIFFUSION. Our studies of the spread of the NYC short-a system and the Northern Cities Chain Shift have allowed us to differentiate the diffusion of linguistic change across communities from the transmission of sound change within the speech community. At the outset, it was argued that change from below is driven by the continuous process of incrementation by children, who reproduce and advance their parents' system. Such incrementation can be quite rapid, so that a vowel can move from low to high position in the course of three generations; yet it preserves the integrity of the system being acquired with the speed, accuracy and faithfulness of first language learners. The incrementation of change means that children learn to talk differently from their parents and in the same direction in each successive generation,. This can happen only if children align the variants heard in the community with the vector of age: that is, they grasp the relationship: the younger the speaker, the more advanced the change. With such interrelated chain shifts as the NCS the various elements advance together.

On the other hand, contact across communities involves learning, primarily by adults, who acquire the new variants of the originating community in a somewhat diluted form. As summarized in the first section of this paper, recent studies of language change across the lifespan show us that adults are capable of changing their language, but at a much slower rate than children. Adult learning is not only slower, but it is also relatively coarse: it loses much of the fine structure of the linguistic system being transmitted. We can now address the question, what kinds of population structures and movements set the conditions for transmission or diffusion?

This inquiry first examined the short-a system of New York City, which has been transmitted within that city with no recorded changes from 1896 to the present. The geographic uniformity of the NYC speech community, from Queens and the Bronx to Jersey City and Newark, suggests the uniform conditions under which an unbroken sequence of parent to child transfers can take place. The fact that the original population absorbed very large numbers of European immigrants and still maintained this continuity is a tribute to the force of the Doctrine of First Effective Settlement (Zelinsky 1992). It also points out that the concept of 'unbroken sequence' does not imply that all transmission is within the nuclear family. Second generation 
children of non-native speakers are capable of disregarding their parent's non-native features from such an early age that they become first dialect speakers of the local vernacular (Labov 1976). It appears that children of native speakers of other dialects cannot match this performance (Payne 1976). ${ }^{43}$

The Inland North is a much larger territory, encompassing an area of 88,000 square miles and 34,000,000 people. How we can we account for the uniformity of the vowel system and its directions of age throughout this vast area? The history of this settlement area associates this uniformity with the migration of intact communities westward, in which entire cohorts of children, parents, kin and communal groups moved together. In his history of the westward migration, Richard Lyle Power (1953:14) points out that

Mass migrations were indeed congenial to the Puritan tradition. Whole parishes, parson and all, had sometimes migrated from Old England. Lois Kimball Mathews mentioned 22 colonies in Illinois alone, all of which originated in New England or in New York, most of them planted between 1830 and 1840 .

The Yankee migration to the Inland North continued the cultural pattern of New England settlement described by David Hackett Fischer (1989) as a largely urban movement with a stronger emphasis on the nuclear family than is found in competing traditions. ${ }^{44}$ New England folkways were transmitted intact in the course of these migrations (Fischer 1989, Frazer 1993, Carnes and Garraty 1996, Labov 2004). Uniform transmission is favored by two measures of stability of the community of New England settlers provided by Fischer, high persistence ${ }^{45}(75-96 \%)$ and low internal migration (1989:814-15). We can attribute the uniformity of the phonology of the Inland North to the continuity of transmission within the migrating families over the past century and a half, in which sound changes are steadily incremented by child language learners. This is the social structure that supports linguistic transmission over many generations.

From our account of the initiating conditions for the NCS in western New York state, we know that this westward migration also absorbed substantial numbers of speakers of other dialects. While we recognize that the NCS is a system of mutually interactive dependencies of some complexity, it does not have the 
grammatical and lexical complexity of split short-a systems, and the social conditions for intact transmission may not be as stringent.

The uniformity of the vowel systems in cities of the Inland North may be contrasted with the wide variety of systems found in the Midland. Widely different patterns and directions of change are to be found in Philadelphia, Pittsburgh, Columbus, Cincinnati, Indianapolis and St. Louis (ANAE Ch. 19). Midland linguistic heterogeneity may be correlated with a pattern of westward migration that contrasts with the Yankee pattern just described. The initial Quaker settlers moving westward from Philadelphia placed a strong emphasis on the creation of farm communities, while the other component of Midland settlement - the back country population of the Upland South - created even smaller units of isolated households. For Quaker populations, Fischer shows only moderate persistence (40-60\%) and low levels for the Upland South (25-40\%).

Nevertheless, large Midland cities did form, as various combinations of trade and travel brought populations together from various areas. The structure of the traditional St. Louis dialect differentiates it from all other Midland cities. It is not the result of large-scale migration from any one region, but the result of a mixture of Southern, Midland and Northern speakers in the second half of the $19^{\text {th }}$ century (Frazer 1978; Murray 1993, 2002). It is undoubtedly the Northern component that distinguishes St. Louis from the surrounding area. Frazer 1978 finds that St. Louis and the adjoining counties of Illinois form a speech island in regard to eight Northern lexical items ${ }^{46}$ and several features of pronunciation that mark the area as Northern as opposed to South Midland: (1)/aw/ in south, down, etc. is not fronted; (2) /iw/ in dew, etc. is not fronted; (3) /oh/ does not have a back upglide, (4) /ay/ is not monophthongal before resonants, and (5) the front short vowels are not ingliding. None of these are elements of the NCS, but they suggests that St. Louis would be receptive to a chain shift that originated in the Northern phonological system. ${ }^{47}$

Frazer 1979 points to ideological factors that reinforced the effect of Northern phonology on speakers in St. Louis and the bottom, particularly those of German origin. The Yankee anti-slavery ideology was attractive to the Germans of St. Louis, who shifted from the Democratic to the Republican party in the election of $1860^{48}$. 
We can therefore project a receptivity to Northern influence from a period well before the development of the NCS in the middle of the $20^{\text {th }}$ century. But the diffusion to St. Louis of the uniform, communally created Inland North dialect was not accomplished by a communal migration. Rather, we must suppose continued contact through the movement of adults, largely commercial, along the corridor now centered on Route I$55 .^{49}$ This is the social context that is associated with a partial transfer of the structure being borrowed.

The diffusion of specific linguistic structures is one of many changes that spring from adult language contact. Trudgill 1986 describes the various scenarios of dialect leveling (the elimination of marked variants), simplification, and their combination in koinéization. Such cases represent more radical losses of structural features than those we have dealt with here. The diffusion of the short-a pattern or the NCS implies the expansion of marked forms into an environment that is receptive to them, and does not require radical deletions or reversals to accommodate them. All of these contact phenomena share the common marks of adult language learning: the loss of linguistic configurations that are reliably transmitted only by the child language learner.

6. Prospectus. This report began with the observation that both family tree models and wave models are needed to account for the history and relatedness of language families. Family tree models are generated by the transmission of changes internal to the system of the speech community, while the wave model reflects the effects of diffusion through language contact. We then considered the general consensus of a strong constraint against the diffusion of language structure in language contact. The main thrust of the paper is to advance an explanation for this difference in attributing internal developments to generational learning--the incrementation of change in an unbroken sequence of parent-to-child transmission, and assigning the major effects of diffusion to the results of extra-generational learning. If this is the case, it follows that the results of language contact will be slower, less regular, and less governed by structural constraints than the internal changes that are the major mechanism of linguistic diversification in the family tree 
model. The difference will still be a matter of degree, since recent studies of language change across the lifespan have shown that adults do participate in ongoing change, more sporadically and at a much lower rate than children.

When language forms are transmitted by contact of single adults or individual families, less regular transmission can be expected. The cases studied here suggest the basic reason why structural borrowing is rare: the adults who are the borrowing agents do not faithfully reproduce the structural patterns in the system they are borrowing from.

The main body of the paper applies this thinking to the study of dialect diffusion, focusing on two cases found in the data of the Atlas of North American English. There is evidence that the complex short- $a$ tensing system of New York City has diffused outward to four different areas. The resulting systems resemble that of New York City in its superficial outline - the phonetic conditioning of tensing by the following segment--but differ from the original model in the absence of grammatical conditioning, the open syllable constraint and specific lexical exceptions. The Northern Cities Shift developed simultaneously in all areas of the Inland North. The chain shifting mechanism operates with a high degree of consistency, linking the movements of six vowels in an overall rotation. But the transmission of the system along the St. Louis corridor produces a more irregular result, indicating that the individual sound changes are diffusing individually rather than as a system.

To pursue these issues further, it would be helpful to know more about the limitations on children's ability to learn new dialects and on adults' inability to learn them. Our knowledge of the diffusion of mergers is particularly inadequate, both for adults and children. Most sociolinguistic studies concern It has been indicated above that children of non-local but native speakers of English can acquire native competence in a second dialect except for grammatically conditioned, lexical distributions (Payne 1976, 1980). It was also suggested that children of non-native speakers are not so limited. This differentiation may not exist for the acquisition of chain shifts, given the uniformity of the Northern Cities Shift across a large section of the United States. This issue may be resolved by replications of the Payne, Oyama, 
and Kerswill and Williams studies in a city of the Inland North. Near-mergers have now been found in many communities

Further studies of such communities may add to our appreciation of the largescale consequences of changes in linguistic competence across the lifespan.

\section{REFERENCES}

Aikhenvald, AleXandra Y. 2002. Language Contact in Amazonia. New York: Oxford University Press.

Ash, Sharon. 2002. The distribution of a phonemic split in the Mid-Atlantic region: Yet more on short A. University of Pennsylvania Working Papers in Linguistics 8.3: Papers from NWAV 30, ed. by Daniel Ezra Johnson and Tara Sanchez, page numbers. Philadelphia: Penn Linguistics Club.

Auer, PETER AND Frans Hinskens. 1996. The convergence and divergence of dialects in Europe. New and not so new developments in an old area. Sociolinguistica 10:1-30.

BABBITT, E. H. 1896. The English of the lower classes in New York City and vicinity. Dialect Notes 1:457-64.

Bailey, GuY, Tom Wikle, Jan TILlery AND Lori SAND. 1993. Some patterns of linguistic diffusion. Language Variation and Change 5:359-390.

BANUAZIZI, ATISSA AND Miriam LiPSON. 1998. The tensing of /ae/ before /1/: an anomalous case for short-a rules of white Philadelphia speech. Papers in Sociolinguistics: NWAVE-26 à l'Université Laval, ed. by Claude Paradis et al, 41-51. Québec: Editions Nota Bene.

Berger, Marshall D. 1980. New York City and the ante-bellum South: the maritime connection. International Linguistic Association 31(1): 47-53.

Blanc, HaIM. 1964. Communal dialects in Baghdad. (Harvard Middle Eastern Monographs, X). Cambridge, Harvard University Press. 204 pp.

Blankenhorn, M.. A. 1950. Visit to the grave of Daniel Drake. Bulletin of the Historical and Philosophical Society of Ohio 8:297-300.

BloOMFIELD, LeONARD. 1933. Language. New York: Henry Holt.

BoBerg, Charles. 2000. Geolinguistic diffusion and the U.S.-Canada border. Language Variation and Change 12:1-24.

BoBERG, CHARLES. 2004. Real and apparent time in language change: late adoption of changes in Montreal English. American Speech 79:250-269.

Boberg, Charles and Stephanie M. Strassel. 2000. Short-a in Cincinnati: a change in progress. Journal of English Linguistics 28:108-126.

BRITAIN, DAVID. 1997. Dialect contact, focusing and phonological rule complexity: the koineisation of Fenland English. Penn Working Papers in Linguistics: A selection of papers from NWAVE 25, 4:141-169.

CAllary, RoBert E. 1975. Phonological change and the development of an urban dialect in Illinois. Language in Society 4:155-170. 
CAMPBELL, LYLE. 1993. On proposed universals of grammatical borrowing. Historical Linguistics 1989: Papers from the 9th International Conference on Historical Linguistics, ed. by J. Aertsem and R. Jeffers, 91-109. Amsterdam: John Benjamins.

CARNES, MARK C. AND JOHN A. GARRATY. 1996. Mapping America's past: a historical atlas. New York: H. Holt.

CARVer, Craig M. 1987. American regional dialects: A word geography. Ann Arbor: U of Michigan Press.

Cedergren, Henrietta. 1988. The spread of language change: Verifying inferences of linguistic diffusion. Georgetown University Round Table on Language and Linguistics, 45-60. Washington, DC: Georgetown University Press.

COHEN, PAUL. 1970. The tensing and raising of short (a) in the metropolitan area of New York City. Columbia University Master's Essay.

Di PaOlo, MARIANNA. 1988. Pronunciation and categorization in sound change. Linguistic Change and Contact: NWAVXVI, ed. by K. Ferrara et al. 84-92. Austin, TE: Dept of Linguistics, U. of Texas.

DuBOIS, SYLVIE AND BARBARA HoRVATH. 1998. Let's think about Dat: Inerdental fricatives in Cajun English. Language Variation and Change 10:245-261.

DYEN, ISIDORE AND GUY JUCQUOIS (eds.) 1973. Lexicostatistics in genetic linguistics II: Proceedings of the Montreal Conference. Montreal: Centre de recherches mathématiques, Université de Montréal.

ECKERT, PENELOPE. 1988. Adolescent social structure and the spread of linguistic change. Language in Society 17:183-208.

ECKert, PeneloPe. 1999. Linguistic Variation as Social Practice, Oxford: Blackwell.

Ferguson, Charles A. 1975. 'Short a' in Philadelphia English. Studies in linguistics in honor of George L. Trager, ed. by M. Estellie Smith, 259-74. The Hague: Mouton.

Fischer, DaVID HaCKetT. 1989. Albion's seed: Four British folkways in America. Oxford: Oxford University Press.

Frazer, Timothy C. 1978. South Midland pronunciation in the North Central states. American Speech 53:40-48.

FraZer, Timothy C. 1979. The speech island of the American bottoms: A problem in social history. 54:185-93.

Frazer, Timothy C. (ed.) 1993. 'Heartland' English. Tuscaloosa: University of Alabama Press.

Gordon, Matthew J. 2001. Small-town values and big-bity Vowels: A study of the Northern Cities Shift in Michigan. Publication of the American Dialect Society 84.

GUY, JACQUES B. M. 1982. Bases for new methods in glottochronology. Papers from the Third International Conference on Austronesian Linguistics, Vol. 1, ed. by Amran Halim et al, 283-314. Pacific Linguistics, C-74.

HALle, MorRis. 1962. Phonology in generative grammar. Word 18:54-72.

HeEringa, Wilbert And John Nerbonne. 2001. Dialect areas and dialect continua. Language Variation and Change 13:375-400.

HENDERSON, ANITA. 1996. The short-a pattern of Philadelphia among African American speakers. Penn Working Papers in Linguistics 3:127-140.

HEROLD, RUTH. 1990. Mechanisms of merger: The implementation and distribution of the low back merger in Eastern Pennsylvania. University of Pennsylvania dissertation. 
Herzog, Marvin I. 1965. The Yiddish Language in Northern Poland. Bloomington \& The Hague: International Journal of American Linguistics 31.2, Part 2).

Hock, HaNs HeNRICH AND BRIAN JosePH. 1996. Language History, Language Change and Language Relationship. Berlin: Mouton/de Gruyter.

Hockett, Charles. 1958. A Course in Modern Linguistics. New York: MacMillan.

HoENIGSWALD, HeNRY. 1960. Language change and linguistic reconstruction. Chicago: University of Chicago Press.

JACKSON, JEAN 1974. Language identity of the Colombian Vaupés Indians. Explorations in the Ethnography of Speaking, ed. by Richard Bauman and Joel Sherzer, 50-64. Cambridge: University Press.

JANDA, RICHARD D. AND BRIAN D. JOSEPH. 2001. Reconsidering the canons of soundchange: Towards a 'Big Bang' theory. Selected Papers from the 15th International Conference on Historical Linguistics, ed by B. Blake and K. Burridge, 205-19. Amsterdam: John Benjamins.

JOHNSON, JACQUELINE S. AND ELISSA L. NEWPORT. 1989. Critical period effects in second-language learning: The influence of maturational state on the acquisition of English as a second language. Cognitive Psychology 21: 60-99.

JosePH, BRIAN D. 2000. Processes of Spread for Syntactic Constructions in the Balkans. Balkan Linguistik: Synchronie und Diachronie, ed. by C. Tzitzilis \& C. Symeonidis, 139-50. University of Thessaloniki, Greece.

KERSWILL, PAUL. 2004. Dialect leveling and geographical diffusion in British English. Social Dialectology: In honour of Peter Trudgill, ed. by David Britain and Jenny Cheshire, 223-43. Amsterdam; John Benjamins.

KING, RUTH. 2000. The lexical basis of grammatical borrowing: a Prince Edward Island French case study. Amsterdam: John Benjamins.

KIPARSKY, PAUl. 1988. Phonological change. Linguistics: The Cambridge Survey, ed. by Frederick Newmeyer, 363-415. Cambridge: Cambridge University Press.

KORN, BERTRAM W. 1969. The early Jews of New Orleans. Waltham MA: American Jewish Historical Society.

Kurath, Hans And Raven I. McDavid, JR. 1961. The Pronunciation of English in the Atlantic States. Ann Arbor: University of Michigan Press.

KurAth, HANS. 1949. A word geography of the Eastern United States. Ann Arbor: University of Michigan Press. 88 pp. \& 163 full-page maps.

LABOV, WiLliam. 1966. The social stratification of English in New York City. Washington D.C.: Center for Applied Linguistics. [Second edition 2006, Cambridge University Press].

LABOV, WiLliAM. 1976. The relative influence of family and peers on the learning of language. Aspetti sociolinguistici dell' Italia contemporanea, ed. by R. Simone et al. Rome:Bulzoni.

LABOV, WILLIAM. 1989a. The child as linguistic historian. Language Variation and Change 1: 85-97.

LABOV, WILliAM. 1989b. The exact description of the speech community: short a in Philadelphia. Language Change and Variation, ed. by Ralph Fasold and Deborah Schiffrin, 1-57. Washington, Georgetown University Press.

LabOV, William. 1991. The three dialects of English. New Ways of Analyzing Sound Change, ed. by Penelope Eckert, 1-44. New York: Academic Press. 
Labov, William. 1994. Principles of linguistic change. Volume 1: Internal factors. Oxford: Blackwell.

Labov, William. 2001. Principles of linguistic change. Volume 2: Social factors. Oxford: Blackwell.

LABOV, WiLliam. 2004. Yankee cultural imperialism and the Northern Cities Shift. Paper given at Modern Language Association Annual Meeting, Philadelphia.

Labov, William, Mark Karan AND COREY Miller. 1991. Near-mergers and the suspension of phonemic contrast. Language Variation and Change 3:33-74.

Labov, William, Sharon Ash And Charles Boberg. 2006. Atlas of North American English: Phonology and Sound Change. Berlin: Mouton/de Gruyter.

Labov, William, Malcah Yaeger \& Richard Steiner. 1972. A quantitative study of sound change in progress. Philadelphia: U. S. Regional Survey.

LAFERRIERE, MARTHA. 1979. Ethnicity in phonological variation and change. Language 55:603-17.

Liebling, A. J. 1961. The Earl of Louisiana. New York: Simon and Schuster.

LightFOOT, DAVID. 1997. Catastrophic change and learning theory. Lingua 100:171-192.

LighTFOOT, DAVID. 1999. The development of language : acquisition, change, and evolution. Oxford: Blackwell.

Linguistic SOCIETY OF AMERICA Bulletin. March 1997.

MARTINET, ANDRÉ. 1955. Êconomie des changements phonétiques. Berne: Francke.

McNaBB, Donnald And Louis E. MAdÈRE. 1983. A History of New Orleans. http://www.mdere.com/history.html\#012.

MODARESSI, YAHYA. 1978. A sociolinguistic investigation of modern Persian. University of Kansas dissertation.

MORAVCSIK, EDITH. 1978. Language contact. Universals of human language, vol 1, ed. by Joseph H. Greenberg, 93-122. Stanford, California: Stanford University Press.

Moulton, William G. 1960. The short vowel systems of Northern Switzerland: a study in structural dialectology. Word 16:155-182.

Murray, Thomas E. 1993. The language of St. Louis, Missouri: Dialect mixture in the urban Midwest. 'Heartland' English, ed. by Timothy C. Frazer, 125-36. Tuscaloosa: University of Alabama Press.

MurRAy, ThOMAS E. 2002. Language variation and change in the urban midwest: The case of St. Louis, Missouri. Language Variation and Change 14:347-361.

NeWPORT, ELISSA L. 2002. Critical periods in language development. Encyclopedia of Cognitive Science, ed. by L. Nadel, 737-40. London: Macmillan.

OYAMA, SUSAN. 1973. A sensitive period for the acquisition of a second language. Harvard University dissertation.

PAYNE, ARVILLA. 1976. The acquisition of the phonological system of a second dialect. University of Pennsylvania dissertation.

PAYNE, ARVILlA. 1980. Factors controlling the acquisition of the Philadelphia dialect by out-of-state children. Locating language in time and space, ed. by William Labov, 143-78. New York: Academic Press.

Pederson, Lee, Susan McDaniel and Carol Adams (eds.) 1986. Linguistic Atlas of the Gulf States. 7 vols. Athens, Ga: University of Georgia Press.

POWER, RICHARD L. 1953. Planting Corn Belt culture: The impress of the Upland Southerner and Yankee in the Old Northwest. Indianapolis: Indiana Historical Society. 
Ringe, Donald, TANDY WARnOW AND ANNE TAYLOR. 2002. Indo-European and computational cladistics. Transactions of the Philological Society 100:59-129.

ROBERTS, JULIA. 1993. The acquisition of variable rules: $t$,d deletion and -ing production in preschool children. University of Pennsylvania dissertation.

RoBerts, JUlia AND WiLliam LABOV. 1995. Learning to talk Philadelphian: Acquisition of short a by preschool children. Language Variation and Change 7:101-112.

SANKOFF, GILlian. 2002. Linguistic outcomes of language contact. Handbook of Sociolinguistics, ed. by Jack Chambers, Peter Trudgill \& Natalie Schilling-Estes, 63868. Oxford: Blackwell.

SANKOFF, GILLIAN. 2004. Adolescents, young adults and the critical period: two case studies from 'Seven Up'. Sociolinguistic variation: Critical reflections, ed. by Carmen Fought, 121-39. Oxford: Oxford University Press.

SANKoff, Gillian, HÉlÈne BlondeAU AND AnNe CHARITy. 2001. Individual roles in a real-time change: Montreal (r>R) 1947-1995. 'r-atics: Sociolinguistic, phonetic and phonological characteristics of /r/. Hans van de Velde \& Roeland van Hout (eds.), 141-158. Etudes \& Travaux 4.

SCHMIDT, JOHANNES. 1871. Zur Geschichte des indogermanischen Vocalismus (Part I). Weimar: H. Böhlau.

Scovel, Thomas. 2000. A critical review of the critical period research. Annual Review of Applied Linguistics 20: 213-223.

SCOVILlE, JoHn. 1870. The old merchants of New York City, by Walter Barrett, clerk. 5 vols. New York: Carleton.

SHEPARD, LEE. 1949. When, and by whom, was Cincinnati founded? Bulletin of the Historical and Philosophical Society of Ohio 7: 28-34.

SHEPARD, LEE. 1957. News from North Bend: some early letters. Bulletin of the Historical and Philosophical Society of Ohio 15: 316-329.

SJODAHL, LARS H. 1964. The Kibbys and Kibbeys of early Cincinnati. Cincinnati Historical Society Bulletin 22:38-40.

Sorensen, Arthur. 1967. Multilingualism in the North West Amazon. American Anthropologist 69:670-84.

StEVEns, HARRY R. 1952. Cincinnati's founding fathers: Isaac Burnet. Bulletin of the Historical and Philosophical Society of Ohio 10:231-239.

THOMASON, SARAH AND TERRENCE KAUFMAN. 1988. Language contact, creolization, and genetic linguistics. Berkeley: University of California Press.

Trager, GeOrge L. 1930. The pronunciation of 'short A' in American Standard English. American Speech 5:396-400.

TRAGER, GEORGE L. 1934. What conditions limit variants of a phoneme? American Speech 9:313-315.

Trager, GeORGE L. 1942. One phonemic entity becomes two: the case of 'short a'. American Speech 17:30-41.

Trudgill, Peter. 1974. Linguistic change and diffusion: description and explanation in sociolinguistic dialect geography. Language in Society 3:215-246.

TrudgiLl, Peter. 1986. Dialects in contact. Oxford: Blackwell.

Trudgill, Peter. 1988. Norwich revisited: recent linguistic changes in an English urban dialect. English World-Wide 9:33-49. 
TRUdGiLl, PETER. 1996. Dialect typology: isolation, social network and phonological strucure. Towards a social science of language: Papers in honor of William Labov, Vol. 1, ed. by Gregory Guy, Crawford Feagin, and John Baugh, 3-22. Amsterdam: John Benjamins.

Trudgill, PETER. 2004. New-dialect formation: the inevitability of colonial Englishes. Oxford: Oxford University Press.

WeINREICH, URIEL. 1968. Languages in contact: Findings and problems. The Hague: Mouton. [Originally published as Publications of the Linguistic Circle of New York, no. 1, 1953.].

Wolfram, Walt and Natalie SchiLling-Estes. 2003. Dialectology and linguistic diffusion. The Handbook of Historical Linguistics, ed. by Brian Joseph and Richard Janda, 713-35. Oxford: Blackwell.

Zelinsky, Wilbur. 1992. The Cultural Geography of the United States. A Revised Edition Englewood Cliffs, NJ: Prentice Hall. 


\section{ENDNOTES}

${ }^{1}$ The parenthetical insertion '(or dialect)' should not be taken as an extension of the family tree model, but simply conforms to the general linguistic position that there is no substantive difference between language and dialect; see LSA resolution on the Oakland 'Ebonics' Issue (LSA 1997). RWT insert this phrase in line with their general emphasis on the evidence drawn from sociolinguistic studies of change in progress at the dialect level.

${ }^{2}$ This terminology does not imply higher or lower in the socioeconomic scale. Changes from above may involve the diffusion of nonstandard elements from other systems, as in the recent spread of London features to other British cities (Trudgill 1974).

${ }^{3}$ It has been argued that branches of a family tree can become differentiated by random drift after separation (Hockett 1958). The general rates of lexical replacement (Dyen and Jucquois 1973, Guy 1982) ensure that separated languages or dialects will eventually drift apart. However, language changes move with such speed (from one end of the vowel space to the other in three or four generations), and with such clear directionality that random drift seems an implausible mechanism.

Furthermore, studies of change in progress show differentiation of dialects in close contact with each other (e.g., across the North/Midland line, ANAE Ch. 11). RWT argue that the principles of descent used in their analysis will apply even when there is no 'clean separation.'

${ }^{4}$ Halle 1962 argued that linguistic change is the result of children's imperfect learning in another sense: that late additions to adults' grammar are re-organized by children as a simpler model, which does not exactly match the parents' original grammar. Although Lightfoot $(1997,1999)$ argues for this model as a means of explaining completed changes, such a process has not yet been directly observed in the study of changes in progress.

${ }^{5}$ A map of language variation is merely a static representation of a phenomenon whose most salient characteristic is its fluidity. It is an almost seamless fabric covering the land. A person traveling southward from Superior, Wisconsin, to Mobile, Alabama, would be aware of the differing speech patterns but would not be able to say at what points along the route the changes occurred ... What follows, then, is not the definitive description of regional dialects of America, because such a description is impossible. It is merely one attempt to seize the linguistic river as it flowed through.' (Carver 1987, p. 19.)

${ }^{6}$ More precisely, adults borrow observable elements of language, the same elements that can be socially evaluated. The objects of social evaluation are at a level one step more abstract than words or sounds. The adult community assigns prestige or stigma to the word stem, irrespective of its appearance in a word with various inflections. Thus piss is not considered more or less vulgar than pisses. Adults also assign prestige or stigma to the use of specific allophones in a given phoneme. The sound [i:ə] is stigmatized in bad but not in idea.

${ }^{7}$ Brian Joseph (p.c. 6/08/06) points out that the issue of grammatical vs. lexical borrowing may be moot in current linguistic theories in which structures are located in the lexicon 
${ }^{8}$ Trudgill's gravity model described the Hemnesberget development and the spread of non-standard features from London. It has not been as successful in other cases (Callary1975, Boberg 2000). The more general 'cascade' model in which change proceeds from the largest to next largest city in an area has proved more general, but other studies indicate that it is only one of many possible models of territorial diffusion (Bailey, Wikle and Sand 1993).

${ }^{9}$ For other variables, it may be the frequency or the scope that is incremented.

${ }^{10}$ Montreal English may be an exception (Boberg 2004), along with some sections of the Mexican-American community in the U.S.

${ }^{11}$ Tense is used here as a cover term for a complex association of phonetic features: raising, fronting, lengthening and the development of an inglide, as opposed to lax: a short low front monophthong.

${ }^{12}$ Babbitt 1896 observed older New Yorkers with a higher vowel in broad-a words than others, but for the majority, all words before front nasals, voiced stops and voiceless fricatives were tensed equally, except for function words (p. 461).

${ }^{13}$ Newark, along with Jersey City, Hoboken and Weehawken, is fully representative of the NYC system.

${ }^{14}$ The steady outflow of New Yorkers to the suburbs of Bergen County, NJ and Westchester, NY, has not effectively modified the basic vernacular of those communities. The eastward line of demarcation in Long Island has not been well defined in any recent studies.

${ }^{15}$ There were a number of differences in areas of lexical diffusion, like /oh/ vs. /a/ in walrus, wash, moral.

${ }^{16}$ ANAE interviews carried out in the 1990s in Passaic and Paterson show a uniform nasal system, with tensing before all and only all nasal consonants.

${ }^{17}$ Vowel-initial polysyllabic words are normally lax in NYC; Alex O.'s lax class includes Amtrak and ancestor.

${ }^{18}$ The derivational forms classic and classify are located in the most conservative area of the tense class distribution. If they had been members of the lax class, they would be located at the lower right of the lax group, near Allentown.

${ }^{19}$ John E, was an engineer in a local Albany firm. He was 46 years old when interviewed in 1995.

${ }^{20}$ As one moves away from NYC, words with voiced velar codas frequently shift to the lax class, generalizing the NYC constraint against tensing before $/ \mathrm{y} /$.

${ }^{21}$ The larger sample interviewed by Boberg and Strassel indicates that Cincinnati is retreating from the traditional short- $a$ system. The speakers they interviewed over 50 years of age were completely consistent; those from 31 to 50 years old were consistent only before nasal consonants; otherwise, short-a was tense before the other tensing environments only $60 \%$ of the time. Speakers under 30 years of age showed tensing in the non-nasal environments only $25 \%$ of the time.

Cincinnati then follows the general shift of Midland short-a towards the nasal system, in which tensing takes place before all nasals and only before nasals.

${ }^{22}$ Stites named the city Losantiville; in 1790, two years later, it was renamed Cincinnati.

${ }^{23} \mathrm{I}$ am indebted to an anonymous reviewer for raising this issue. 
${ }^{24}$ The most general formulation is that weak words are exempted from the tense class, defined as words whose only vowel can be shwa (can't is a function word which cannot have shwa, and is never lax). The Philadelphia short-a system is the same as that of Wilmington, Reading and Baltimore (Labov 1989b, 1994; ANAE Ch. $13)$.

${ }^{25}$ A common explanation given for this constraint is that function words are lax in their unstressed form, and that they are lax by analogy in their restressed form. Though this may be a correct explanation, it is recognizably post hoc.

${ }^{26}$ Since Cajun English speakers show substrate influence from French (Dubois and Horvath 1998), one must also consider this as a potential influence on New Orleans in general.

${ }^{27}$ Like many such abbreviations, Dan can be assigned the tense/lax status of the full form Daniel; the glide /y/ only variably closes the syllable in NYC, as in spaniel, annual, With an initial gr- and two following syllables, grandparents is frequently lower than all other tense vowels. After is exceptionally tense in NYC; in New Orleans, it follows the general rule of lax realization of word-initial /æ/ in polysyllables.

${ }^{28}$ Elizabeth G. was a teacher, of French/Irish/German background.

${ }^{29}$ This broadcast is currently available at http://www.amroutes.com/programs/shows/20050316.html

${ }^{30}$ Both directions are of course possible, and it is plausible that palatalization of work, third, etc. is derived from the South, as PEAS shows that it is widely used in several Southern areas.

${ }^{31}$ Korn's book refers to Charleston on 43 pages, Savannah on 5, and Boston on 6 .

${ }^{32} \mathrm{Mr}$. Kohlmeyer referred to an oral tradition in his family that the New York City influence in New Orleans was from a single teacher from Brooklyn who arrived in the 1890's. Marc Caplan of New Orleans told me of an oral tradition in his family that attributed New York City influence to the period late in the nineteenth century when New Orleans docks were rebuilt with the help of large numbers of laborers from New York City. I have found no written evidence for this.

${ }^{33}$ The influence of the Jewish community, detailed above in the historical data, appears phonetically in the raised /oh/ of New Orleans. There is a marked tendency for second and following generations of Jews to raise this vowel to upper mid and lower high position, more so than other ethnic groups: see Labov 1966 for New York City and Laferriere 1979 for Boston.

${ }^{34}$ And wan, the vernacular preterit of win.

${ }^{35}$ ANAE Chapter 8 shows that the distinctions between /hw/ and /w/, /ohr/ and /ohr/, /iw/ and /uw/ have all but disappeared in the United States, although they were strongly maintained in both the North and the South in the records of the midtwentieth century (Kurath and McDavid 1961). The low back merger of /o/ and /oh/ has expanded in some areas with comparable speed. The Philadelphia LVC project interviewed adolescents at a Pottsville recreational park in 1977. When Herold (1990) returned to the same site eleven years later, she found that the percent of those 
judging cot and caught as 'the same' jumped from 17 to $100 \%$ for girls, and from 29 to $67 \%$ for boys.

${ }^{36}$ Herold 1990 provides acoustic analyses of adult speakers with a stable distinction of the low back vowels /o/ and /oh/ and their children with complete merger.

${ }^{37}$ Martin H., of German background, worked as a manufacturer's wholesale representative.

${ }^{38}$ The Northern Cities Chain Shift operating in the Inland North is here assumed to be governed by the mechanical operation of probability-matching by language learners, as described in Labov 2001, Ch. 20. The outcome takes the form of pull shifts and push shifts described in Martinet 1955, but without any purposive intent to preserve contrasts.

${ }^{39}$ The city of Peoria is not far from I-55, but it is not on the direct route.

${ }^{40}$ The Midland distribution is 75 to 1 , but since the null hypothesis for the 9 tokens within the corridor would have fewer than 5 tokens in a cell, Fisher's Exact Test is appropriate, yielding $\mathrm{p}=.00026$.

${ }^{41}$ The difference in homogeneity between the St. Louis corridor and the Inland North has a probability of .0017 by Fisher's Exact Test.

${ }^{42}$ Rose M. was 38 when interviewed in 1994. She had worked as a dancer and a seamstress.

${ }^{43}$ There is of course a limit on how many newcomers a speech community can absorb. 'Dialect swamping' occurs when the incoming population is of the order of ten times the original population, as in the AAVE communities of the North and the coal mining communities of eastern Pennsylvania (Herold 1990).

${ }^{44}$ Mean family size for New England settlements was 7 as compared to 3 for the Virginia Tidewater South and 5 for the Quaker oriented settlements of the Delaware Valley (Fischer 1989:815).

${ }^{45}$ Fischer's 'refined persistence rate' is defined as the percent of living adults persisting through ten years.

${ }^{46}$ Cruller, school leaves out, sick to the stomach, pavement, smearcase, smearcheese, haycock, quarter to.

${ }^{47}$ Figures 13-16 show the boundaries of the Inland North, the region defined by the NCS. However, the Inland North is only a portion of the larger Northern region, in which the preconditions for the NCS are present, but not the shift as a whole.

${ }^{48}$ In nominating Lincoln in 1860, the Republican Party confirmed its opposition to the extension of slavery to newly admitted states.

${ }^{49}$ The inter-state highway I-55, built just after World War II, is now the main route for Chicago-St. Louis travel, but it follows the path of earlier traffic, in particular the Illinois-Central Railroad, which was built in 1856 to connect Cairo in the southern tip of Illinois with Galena and Chicago. 